\title{
Research Paper \\ The Relationship between Addictions to Computer Games with Sleep Disorder in Preschool Children: The Moderating Role of Relationship with Parents
}

\author{
Saloomeh Mortazavi ${ }^{1}$, Hadi Farhadi*2 \\ 1. M.A. in General Psychology, Department of Psychilogy, Isfahan (Khorasgan) Branch, Islamic Azad University, Isfahan, Iran \\ 2. Associate Professor, Department of Psychilogy, Isfahan (Khorasgan) Branch, Islamic Azad University, Isfahan, Iran
}

Citation: Mortazavi S, Farhadi H. The relationship between addictions to computer games with sleep disorder in preschool children: the moderating role of relationship with parents. J Child Ment Health. 2021; 8 (1):61-79.

URL: http://childmentalhealth.ir/article-1-784-en.html
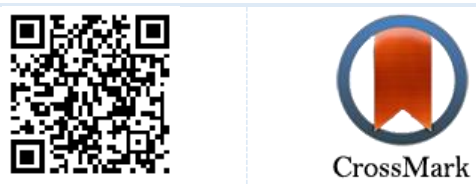

$10.52547 / \mathrm{jcmh} .8 .1 .6$ (2) 20.1001.1.24233552.1400.8.1.6.5

\section{A R T I C L E I N F O}

\section{Keywords:}

Computer addiction, sleep disorders, preschoolers, parental moderator role

Received: 2 Mar 2019 Accepted: 16 Nov 20219 Available: 8 Jun 2021

\section{A B S T R A C T}

Background and Purpose: By developing new technologies, increasing the use of Computer games by children, the variety of these games, and their negative effects on children's sleep, identifying and monitoring games will be crucial. This study aimed to investigate the relationship between Computer Games addiction to sleep disorders in preschool children considering the role of moderating relationships with parents.

Method: This is a correlation study. The sample of this study was 350 mothers of preschool children who were studying in the academic year of 2017-18 in areas 3, 5, and 6 Isfahan and were selected by convenient sampling. In this research, Farhadi computer addiction inventory (2016), Owens and Sprite (2000), and Baby-Baby Relationships (1961), were used. The results were analyzed using Pearson correlation coefficient and regression.

Results: The results of correlation analysis showed that there is a positive and significant relationship between sleep deprivation computer addiction in children with sleep resistance, sleep duration, sleep anxiety, and parasomnia $(\mathrm{P}=0 / 001<0.05)$. However, there was no meaningful relationship with the components of delay in beginning sleep $(\mathrm{P}=0 / 20)$, night-time awakening $(\mathrm{P}=0 / 21)$, sleep disorder $(\mathrm{P}=0 / 05)$ and sleepiness $(\mathrm{P}=0 / 66)$, and the relationship with parents in the over-supporting component relationship with sleep disorders and addiction to computer games has a significant moderating effect $(\mathrm{P}=0 / 0012<0.05)$. However, with the acceptance components of the child $(\mathrm{P}=0 / 94)$, the more aggressive $(\mathrm{P}=0 / 52)$ and rejection of the child $(\mathrm{P}=0 / 34)$ does not have a significant moderating effect $(\mathrm{P}>0.05)$.

Conclusion: The results indicate the positive relationship between sleep disorders and their adverse effects on the child, the way parents work, and the destructive role of computer games addiction. Extreme gambling plays a significant role in the development of problems and intensifying symptoms of sleep disorders, and on the other hand, child withdrawal also results in increased addiction to computer games and sleep disorders.

* Corresponding author: Hadi Farhadi, Assistant prefosoor, Department of Psychilogy, Isfahan (Khorasgan) Branch, Islamic Azad University, Isfahan, Iran.

E-mail: Farhadihadi@yahoo.com

Tel: (+98) 3132276514

2476-5740/ (C) 2021 The Authors. This is an open access article under the CC BY-NC-ND license

(https://creativecommons.org/licenses/by-nc-nd/4.0/). 


\section{Extended Abstract}

\section{Introduction}

Play is the best tool for the growth and flourishing of a child's emotions and the best way to cultivate his emotions and feelings. Computer games are one of the most exciting activities of the present age, and many children and adolescents devote a significant portion of their free time to these games (1). The inflammatory atmosphere of these games and the increase in time spent playing them leads to nervous stimuli that are more than the routine daily capacity of the child and his age and manifests itself in the occurrence of disorders such as sleep disorders. (2). It should be noted that sleep is one of the main physiological and psychological needs and any incorrect behavioral habits that lead to a negative impact on sleep time and quality, irreparable problems, and damage that have a direct impact on the physical and mental condition of the child. Will be accompanied (3). Sleep disorders include day-today problems such as sleep disturbances, drowsiness, nightmares, and panic attacks during sleep, and may also lead to more complex issues such as difficulty breathing and difficulty moving muscles. Sleep disturbance and sleep disorders occur in $40 \%$ of children and 25 to $50 \%$ in preschool children (4). Sleep disorders in children mean an excessive decrease or increase in age-inappropriate sleep, abnormal types of sleep, abnormal behaviors, or the occurrence of abnormal events during sleep (5). Paying attention to the healthy mental relationship of the home environment, the mental health of the child, and the role of communication between parents and children in creating and improving the relationship and controlling the duration of playing games is very fruitful and debatable (15).

Considering the importance of recognizing computer games and their effect on the developmental process of children and conducting limited studies on the position of this study (such as 11 and 19), this study examines the relationship between computer game addiction and sleep disorders in preterm children. The school has mediated communication with parents. By understanding the mechanism of the effect of parental interactions and subsidized games on sleep disorders as well as other children's disorders, it is possible to create a suitable model in using games and parental communication to reduce children's disorders.

\section{Method}

The present study is descriptive and correlational. The statistical population of the present study includes preschool children (5 to 7 years old) in the academic year 2017-18 in Isfahan. The sampling method was randomly selected from three education districts 6, 5, and 3 among the education districts of Isfahan and then from these three districts 350 children (214 girls and 316 boys $-61.1 \%$ girls and / 9). $38 \%$ of the boys were present. The mean age of the children studied was 5.77 with a standard deviation of 0.42 ), selected by convenient sampling. The entry angels of the sample in this study: "The child in the preschool period attend primary school (ages 5 to 7), the child uses computer games (children's playtime varies from 0 to 8 hours), and there are problems with the child's sleep (the number of hours of sleep of these children from 6 to 13 The clock fluctuated (which is not due to physical or mental problems). The mothers completed the Soltani and Farhadi computer game addiction questionnaires (25), the sleep habits of the children of Owens, Spirito, McGuinness, and Nobel (26), and Robert's mother-child relationship assessment scale (27) were distributed among their mothers. It should be noted that if the participants had intellectual disability or other comorbid disorders, or has undergone treatment due to sleep disorders and behavioral problems, they will be excluded from the sample. The results were analyzed using SPSS-21 software. Mean and standard deviation were used for descriptive study, correlation, regression, and hierarchical regression were used to analyze the data.

\section{Results}

Table 1 examines the relationship between computer game addiction and sleep disorders and its components. 
Table 1: Investigating the relationship between computer game addiction and sleep disorders and its components

\begin{tabular}{|c|c|c|c|}
\hline \multirow{2}{*}{ ROW } & \multirow{2}{*}{ VARIABLES } & \multicolumn{2}{|c|}{ ADDICTION TO COMPUTER GAMES } \\
\hline & & Sig & $\mathbf{R}$ \\
\hline 1 & Sleep resistance & $0 / 25$ & $0 / 00$ \\
\hline 2 & Delayed sleep onset & $0 / 06$ & $0 / 20$ \\
\hline 3 & sleep time & $0 / 24$ & $0 / 00$ \\
\hline 4 & Sleep Anxiety & $0 / 24$ & $0 / 00$ \\
\hline 5 & Nights Awake & $0 / 06$ & $0 / 21$ \\
\hline 6 & Parasomnia & $0 / 16$ & $0 / 00$ \\
\hline 7 & Sleep breathing disorder & $0 / 10$ & $0 / 052$ \\
\hline 8 & daily drowsiness & $0 / 66$ & $0 / 02$ \\
\hline 9 & total score of sleep disorder & $0 / 28$ & $0 / 00$ \\
\hline
\end{tabular}

As be seen in the table, there is a positive and significant relationship between computer game addiction and sleep disorders, and with increasing game addiction, sleep disorders increase. There is a positive and significant relationship between computer game addiction and components of sleep duration, sleep resistance, parasomnia, and sleep anxiety. In this study, the relationship between computer game addiction and the components of delayed sleep onset, nocturnal awakening, sleepdisordered breathing, and daily drowsiness was not observed. Table 2 shows the analysis of the hierarchical regression model of research variables.

Table 2 - Analysis of hierarchical regression model

\begin{tabular}{|c|c|c|c|c|c|c|c|c|}
\hline $\begin{array}{c}\text { THE } \\
\text { COMPONENT } \\
\text { UNDER STUDY }\end{array}$ & $\begin{array}{l}\text { MODEL } \\
\text { STAGE }\end{array}$ & VARIABLES & R2 corrected & $\Delta \mathbf{F}$ & $\mathbf{P}$ & B & STANDARD B & $\mathbf{P}$ \\
\hline \multirow{7}{*}{ 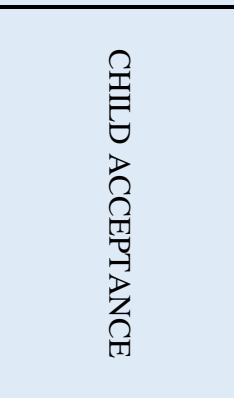 } & \multirow{3}{*}{1} & Model features & 0/077 & $15 / 498$ & $0 / 00$ & & & \\
\hline & & Game addiction & & & & $0 / 008$ & $0 / 282$ & $0 / 000$ \\
\hline & & $\begin{array}{l}\text { Child acceptance } \\
\text { component }\end{array}$ & & & & $-0 / 023$ & $-0 / 045$ & $0 / 382$ \\
\hline & \multirow{4}{*}{2} & Model features & $0 / 074$ & $0 / 004$ & $0 / 947$ & & & \\
\hline & & Game addiction & & & & $0 / 008$ & $0 / 285$ & $0 / 00$ \\
\hline & & $\begin{array}{l}\text { Child acceptance } \\
\text { component }\end{array}$ & & & & $-0 / 020$ & $-0 / 040$ & $0 / 675$ \\
\hline & & $\begin{array}{l}\text { Game addiction * Child } \\
\text { acceptance component }\end{array}$ & & & & $0 / 000$ & $0 / 007$ & $0 / 947$ \\
\hline \multirow[t]{2}{*}{$\begin{array}{c}\text { THE } \\
\text { COMPONENT } \\
\text { UNDER STUDY }\end{array}$} & $\begin{array}{c}\text { Model } \\
\text { stage }\end{array}$ & VARIABLES & $\mathrm{R} 2$ corrected & $\Delta \mathbf{F}$ & $\mathbf{P}$ & $\boldsymbol{\beta}$ & STANDARD $\boldsymbol{\beta}$ & $\mathbf{p}$ \\
\hline & \multirow{3}{*}{1} & Model features & $0 / 085$ & $17 / 186$ & $0 / 00$ & & & \\
\hline \multirow{5}{*}{$\begin{array}{l}3 \\
0 \\
\text { T1 } \\
\tilde{\Xi} \\
\mathbb{0} \\
0 \\
0 \\
0\end{array}$} & & Game addiction & & & & $0 / 007$ & $0 / 274$ & $0 / 000$ \\
\hline & & $\begin{array}{l}\text { More support component } \\
\text { Model features }\end{array}$ & 0/099 & $6 / 395$ & 0/012 & $-0 / 051$ & $-0 / 101$ & $0 / 050$ \\
\hline & \multirow{3}{*}{2} & Game addiction & & & & $0 / 010$ & $0 / 370$ & $0 / 00$ \\
\hline & & More support component & & & & $-0 / 048$ & $-0 / 094$ & $0 / 311$ \\
\hline & & $\begin{array}{l}\text { Game addiction * More } \\
\text { support component }\end{array}$ & & & & $-0 / 007$ & $-0 / 246$ & $0 / 012$ \\
\hline $\begin{array}{c}\text { THE } \\
\text { COMPONENT } \\
\text { UNDER STUDY }\end{array}$ & $\begin{array}{l}\text { Model } \\
\text { stage }\end{array}$ & VARIABLES & $\mathrm{R} 2$ corrected & $\Delta \mathbf{F}$ & $\mathbf{P}$ & $\boldsymbol{\beta}$ & STANDARD $\boldsymbol{\beta}$ & $\mathbf{p}$ \\
\hline \multirow{2}{*}{ 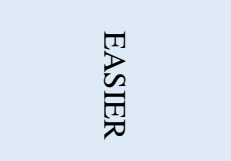 } & \multirow[t]{2}{*}{1} & $\begin{array}{l}\text { Model features } \\
\text { Game addiction }\end{array}$ & $0 / 090$ & $18 / 147$ & $0 / 00$ & 0/007 & $0 / 282$ & $0 / 000$ \\
\hline & & $\begin{array}{l}\text { Easier component } \\
\text { Model features }\end{array}$ & 0/088 & $0 / 405$ & $0 / 525$ & 0/005 & $0 / 089$ & $0 / 018$ \\
\hline
\end{tabular}




\begin{tabular}{|c|c|c|c|c|c|c|c|c|}
\hline & & Game addiction & & & & $0 / 001$ & $0 / 050$ & $0 / 888$ \\
\hline & & Easier component & & & & $0 / 003$ & $0 / 068$ & $0 / 493$ \\
\hline & & $\begin{array}{c}\text { Game addiction } * \text { Easier } \\
\text { component }\end{array}$ & & & & $0 / 001$ & $0 / 236$ & $0 / 525$ \\
\hline $\begin{array}{c}\text { THE } \\
\text { COMPONENT } \\
\text { UNDER STUDY }\end{array}$ & $\begin{array}{c}\text { Model } \\
\text { stage }\end{array}$ & VARIABLES & $\mathrm{R} 2$ corrected & $\Delta \mathbf{F}$ & $\mathbf{P}$ & $\boldsymbol{\beta}$ & STANDARD $\boldsymbol{\beta}$ & $\mathbf{p}$ \\
\hline$\Omega$ & & Model features & 0/088 & $17 / 704$ & $0 / 00$ & & & \\
\hline 西 & 1 & Game addiction & & & & $0 / 007$ & $0 / 282$ & $0 / 000$ \\
\hline$\Xi$ & & Child rejection component & & & & $-0 / 056$ & $-0 / 089$ & $0 / 029$ \\
\hline$\vec{\pi}$ & & Model features & $0 / 087$ & $0 / 913$ & $0 / 340$ & & & \\
\hline$\frac{M}{3}$ & & Game addiction & & & & $0 / 008$ & $0 / 317$ & $0 / 00$ \\
\hline$\widehat{\overbrace{}}$ & 2 & Child rejection component & & & & $-0 / 019$ & $-0 / 037$ & $0 / 695$ \\
\hline Z & & $\begin{array}{l}\text { Game addiction * Child } \\
\text { rejection component }\end{array}$ & & & & $-0 / 003$ & $-0 / 097$ & $0 / 340$ \\
\hline
\end{tabular}

\section{According to Table 2, it can be concluded:}

Part 1: The child acceptance component has a moderating effect on the relationship between sleep disorders and computer game addiction. This hypothesis was rejected, and in other words, the child acceptance component does not have a significant moderating effect on the relationship between sleep disorders and computer game addiction $(\mathrm{P}<0.05)$.

Part 2: The component of hypersensitivity has a moderating effect on the relationship between sleep disorder and computer game addiction. This interaction is significant considering the amount of $\Delta \mathrm{F}$ presented for the second model. Therefore, the components of game addiction and over-support have a direct effect on sleep disorder $(\mathrm{P}<0.05)$, and due to the significant interaction of "game addiction-over-support;" this hypothesis is accepted; in other words, the oversupportive component has a significant moderating effect on the relationship between sleep disorder and computer game addiction ( $\mathrm{P}<0.05)$. That is, children with a high level of over-supportive addiction to computer games have a lesser effect on their sleep disorders than children with a lower level of oversupportiveness.

Part 3: The over-relaxation component has a moderating effect on the relationship between sleep disorders and computer game addiction. This hypothesis is not accepted; and in other words, the over-relaxation component does not have a significant moderating effect on the relationship between sleep disorder and computer game addiction $(\mathrm{P}<0.05)$.
Part 4: The child rejection component has a moderating effect on the relationship between sleep disorder and computer game addiction. This hypothesis is not accepted, and in other words, the child rejection component does not have a significant moderating effect on the relationship between sleep disorder and computer game addiction $(\mathrm{P}<0.05)$.

\section{Conclusion}

This study aimed to investigate the relationship between computer game addictions and sleep disorders in preschool children by considering the moderating role of communication with parents. The results of this study and similar studies indicate a positive relationship between the incidence of sleep disorders and their adverse effects in children, with parental behavior and the destructive role of computer game addiction.

The results of this study and the studies of manifestation and ornamentation (15) and Ikhf et al. (2) show that excessive play has a significant role in causing problems and aggravating the symptoms of sleep disorders. Child rejection will also lead to an increase in computer game addiction and sleep disorders (19). When parents become overly relaxed, they subconsciously make it difficult for their children to develop the effects of sleep disorders. The results of statistics obtained from the moderating role of parents in the occurrence of disorders caused by cyber addiction indicate the impact of the quality of the relationship between parent and child in this regard. Whenever children experience psychological problems in the family environment; they fill the 
void of their relationship needs by becoming more and more inclined to these games. The direct effect of both parameters of over-support and negligence and adverse effects due to the lack of appropriate atmosphere in the psychological environment of the parent-child relationship on the severity of the tendency to play is significant and studied (11).

One of the limitations of the present study is the conservatism and fault of many parents. The lack of access to neutral resources and the limitation of the statistical population to preschool children were other limitations of this study. Researchers interested in this field are recommended to do this research in other academic levels, by conducting clinical interviews and using questionnaires to assess family relationships.

One of the limitations of the present study is the conservatism and imperfection of many parents. This means that parents avoided providing accurate information and tried to protect their children from eating the label of mental problems and to significantly hide the disorders they face; There have also been differing views and biases towards these games in recent years, and differences of opinion have in many cases been signs of unprofessional and pessimistic attitudes that are far from the availability of neutral resources was another limitation of this study. The statistical population of the present study is limited to mothers of preschool children and this is another limitation of this study. Researchers interested in this field are recommended to do this research in other educational levels, conduct clinical interviews and use questionnaires to examine family relationships.

\section{Ethical Considerations}

Compliance with ethical guidelines: This research is extracted from the master thesis of the first author in the field of general psychology, Azad University, Isfahan Branch (Khorasgan) with the code 12321-5-14-04-96, and obtaining all the necessary scientific and executive licenses from the institute relevant, has been done. Also, other ethical considerations such as gaining the informed consent of the participants and maintaining privacy and confidentiality have been fully considered in this study.

Funding: This study was conducted independently and without sponsor.

Authors' contribution: The first author of this article was the main facilitator of this study and the second author was the supervisor and the responsible author. It should be noted that all authors have read and approved the final manuscript.

Conflict of interest: This study did not have any conflict of interest for the authors.

Acknowledgments: Hereby to the officials of the Islamic Azad University, Isfahan Branch (Khorasgan), the officials of the Department of Education, especially the counseling expert who coordinated with the schools to conduct the research questionnaires, as well as the administrative staff, school teachers and all parents and the students who helped us implement this project are appreciated. 
رابطه اعتياد به بازىهاى رايانهاى با اختلال خواب در كود كان ييشدبستانى با در نظر زرفتن نقش تعديل كنند ارتباط با والدين

\author{
r** سالومه مر تضوى'، هادى فرهادى

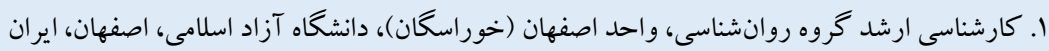

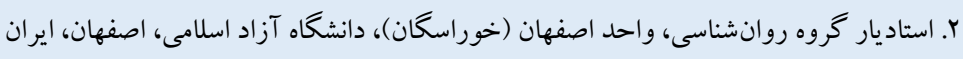

\begin{tabular}{|c|c|}
\hline جكيده & 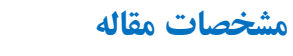 \\
\hline زمينه و هدف: با توسعه فناورى هاى جديد، افزايش استفاده از بازى هاى رايانهاى توسط كود كان، تنوع اين بازىها و تأثيرات منفى آنها بر & كليدوازهها: \\
\hline خواب كود كان، شناسايى و نظارت بر بازى ها بسيار مهم خو اهد بود. بنابراين هدف از اين مطالعه تعيين رابطه اعتياد به بازىهاى رايانهاى و & 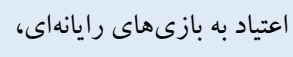 \\
\hline اختلالات خواب در كود كان بيش دبستانى با توجه به نقش تعديل كننده روابط با والدين است. & 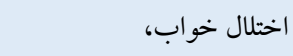 \\
\hline روش: اين يُزوهش از نوع همبستكى است و جامعه آمارى يُزوهش حاضر شامل كود كان ييشدبستانى با حجم نمونه (•ها) نفر است كه به & كود كان بيش دبستانى، \\
\hline روش نمونه گيرى در دسترس انتخاب شدند. در اين يزّوهش از ير سشنامه اعتياد به بازىهاى رايانهاى فرهادى (هوجا)، عادات خواب كودكى & نقش تعديل كنندگى والدين \\
\hline \multicolumn{2}{|l|}{ 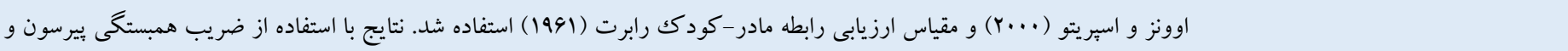 } \\
\hline ركر ريون سلسله مراتبى تحليل شدند. & \\
\hline \multicolumn{2}{|l|}{ يافته ها: نتايج تحليل همبستخى نشان داد كه بين اعتياد به بازىهاى رايانهاى با اختلال خواب در كود كان با مؤلفههاى مقاومت در برابر } \\
\hline \multicolumn{2}{|l|}{ 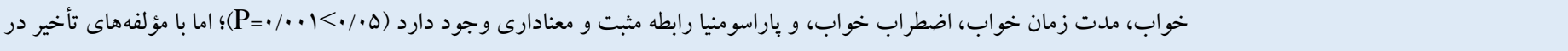 } \\
\hline \multicolumn{2}{|l|}{ 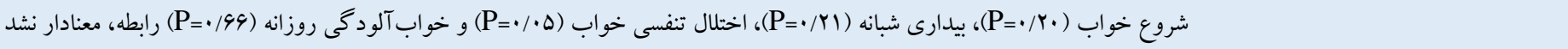 } \\
\hline \multicolumn{2}{|l|}{ و همجحنين ارتباط با والدين در مؤلفه بيش حمايتخرى بر رابطه با اختلال خواب و اعتياد به بازىهاى رايانهاى اثر تعديل گرى معنادارى دارد } \\
\hline \multicolumn{2}{|l|}{ 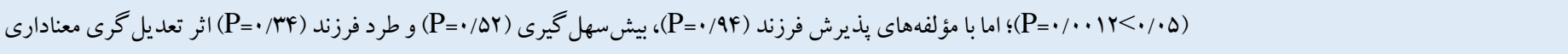 } \\
\hline 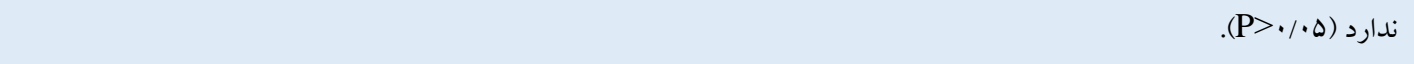 & \\
\hline نتيجه كيرى: نتايج بيانگر رابطه مستقم بروز اختلالات خواب و عوارض سوء ناشى از آن در كود كى، با نحوه عملكرد والدين و نقش مخرب & 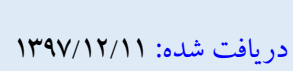 \\
\hline \multirow{2}{*}{ 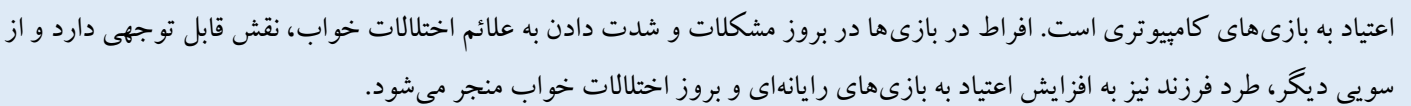 } & 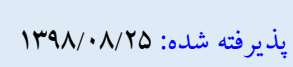 \\
\hline & 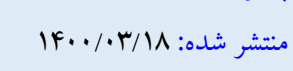 \\
\hline
\end{tabular}

* نويسنده مسئول: هادى فرهادى، استاديار كروه روانشناسى، واحد اصفهان (خوراسكان)، دانشكاه آزاد اسلامى، اصفهان، ايران.

رايانه: Farhadihadi@yahoo.com

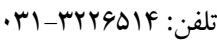


خواب شــامـل مشــكلـات روزمره از جملـه اختلـال در زمـان خوابّ"،

مقلمهه

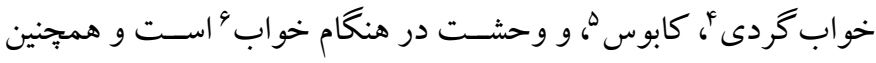

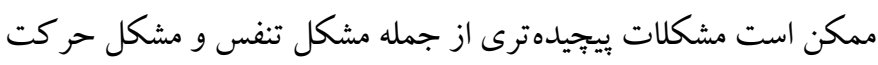

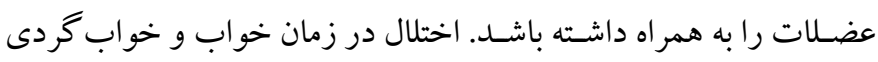
در ميان ·F درصد از كود كان و ها تا •ه درصد از كود كان بيشدبستان رخ مىدهـد (F). اختلالات خواب در كود كان به معناى كاهش يا افزايش

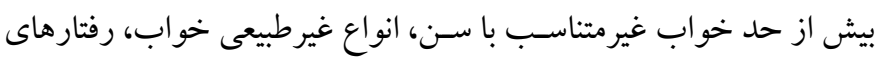

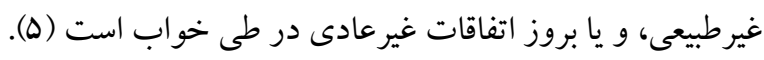

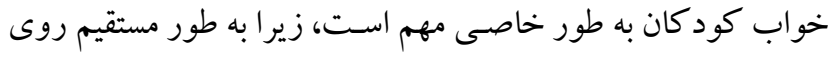

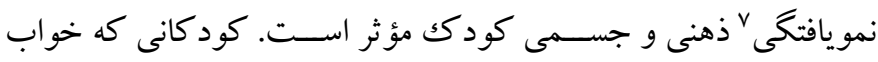

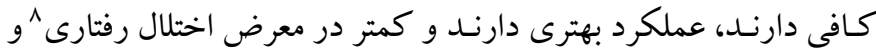
خلقى هستـند. برخى از ئزوهشها نشـان دادهاند كه اسـتفاده از بازىهاى دهري

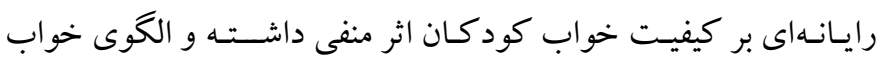

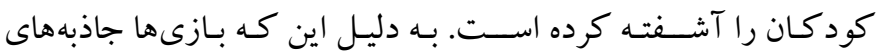
مسـحور كنندهاى دارند، كودكى وقت و انرزى زيادى راصسرف بازى با آنها مى كند؛ حتى بعضسى از كود كان صـبح زودتر از وقت معمول بيدار مى شـوند تا قبل از مدرسـه كمى بازى كنند و يا شـبـها تا ديروقت بيدار

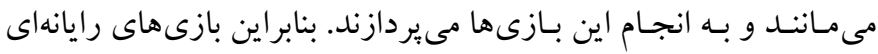
مى تواند باعث بر هم خوردن ســاعات خواب كود كان شــود (9). فرويد

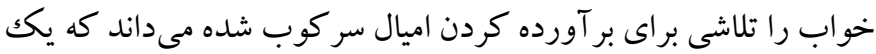

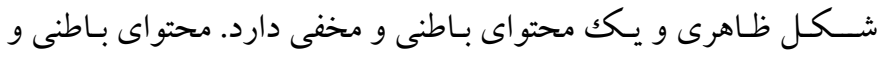

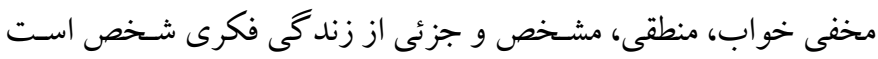

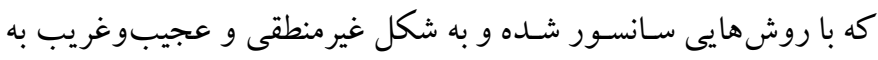

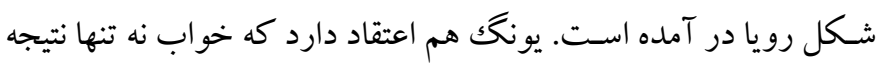
تعارضهاى درونى اسـت، كه در بيشـتر موارد تظاهر اتى از ناخود آكاه

$$
\text { جمعى را در بر دارد (V). }
$$

مى توان گفت كود كك از طريق سر گرم ساختن خود با بازى رايانهاى

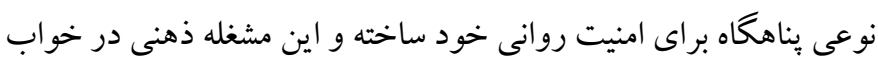

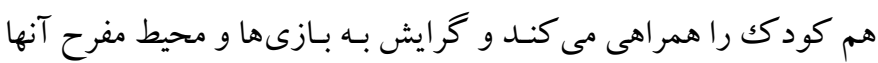

\section{Nightmares}

6. Panic while sleeping

7. Maturation

8. Behavioral disorder

بازى بهترين وسيله براى تحول و شـكوفايى احساسات كودك و بهترين

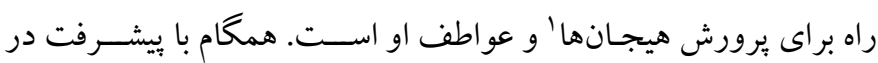

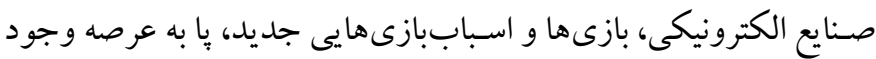

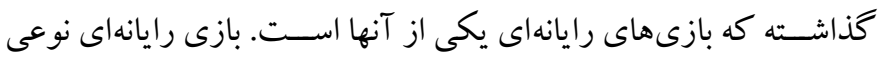

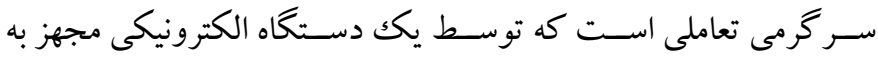

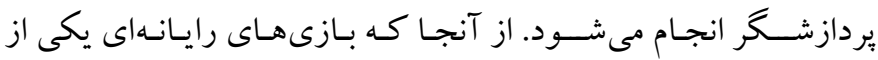

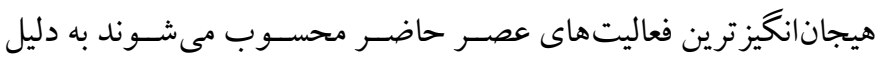

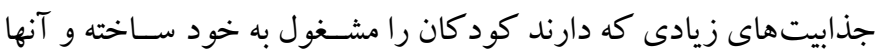
سـاعات زيادى از شـبانهروز را به انجام اين بازىها مى يردازند؛ به طورى

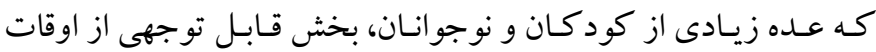
فراغت خود را به اين بازىها اختصاص مىدهند (1).

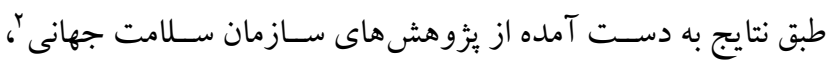

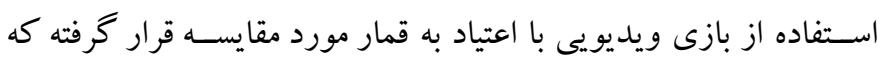

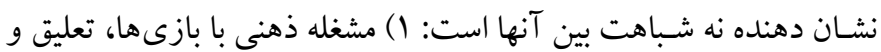
همانندسازى موقعيتهاى بر التهاب دنياى مجازى، Y) افزايش مقدار زمان

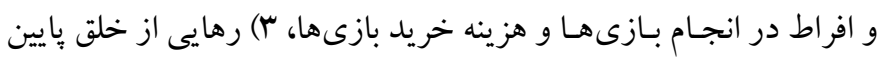

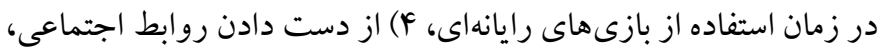

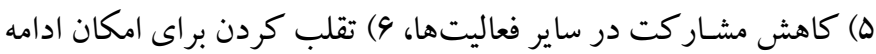

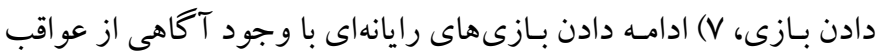

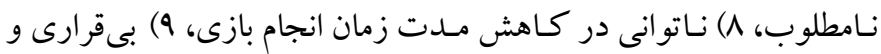

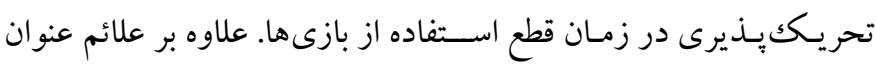

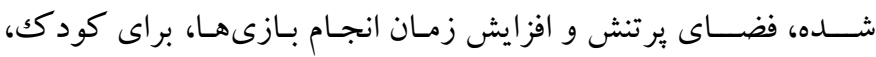
تحريكات عصسبى بيشتر از توان كودكك و شـر ايط سنى او ايجاد مى كند

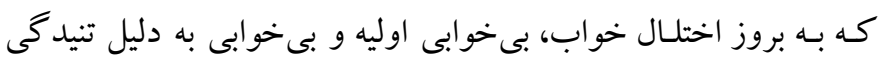

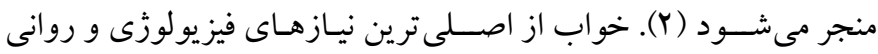

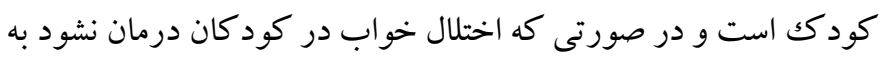
عوارضى جبر اننايذير و يا دست كم بسيار جدى مانند اختلال در توجه و و

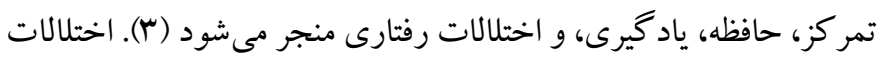

1. Emotion

2. World Health Organization (WHO)

3. Sleep disturbance

4. Sleepwalking 
دور از آسـيبـهاى احتمالى محيط بيرون از منزل باشـند و همين موضـوع

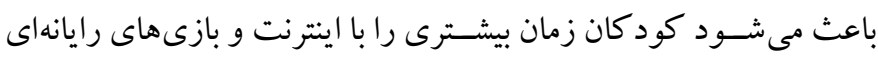

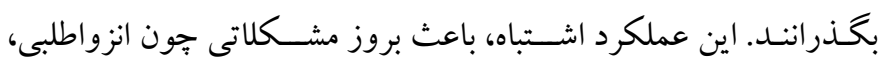

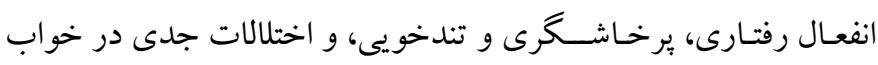

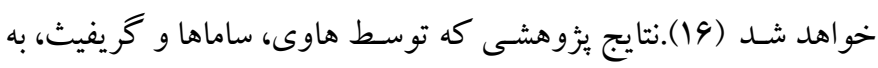

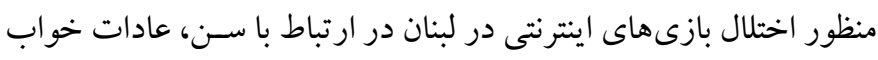

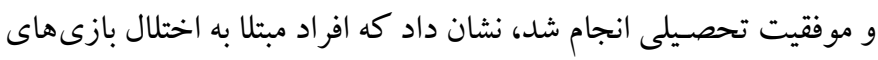

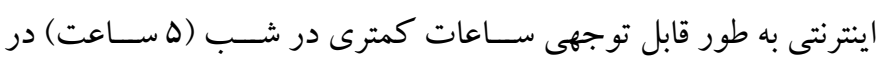

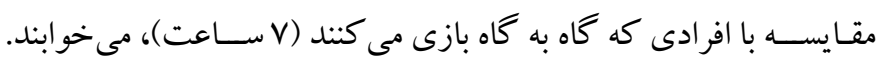

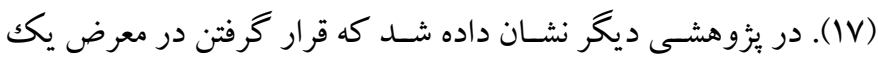

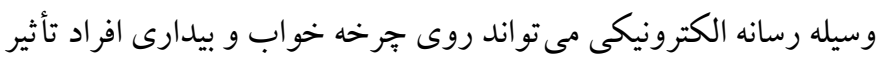

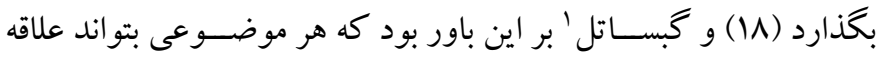

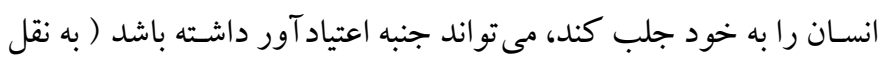
از 19). در يـك مطالعه كه به بررســى وضـعيت كود كان جوانى كه از

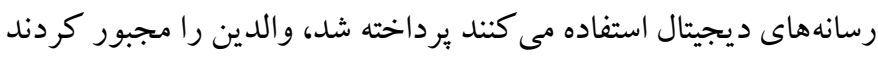

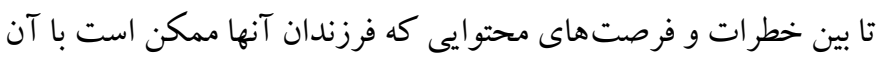

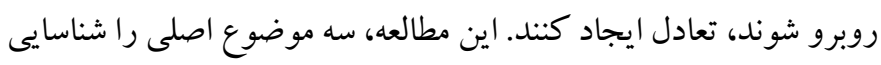

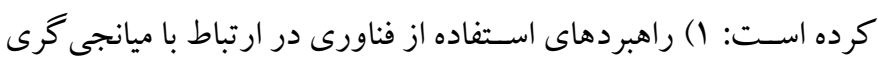

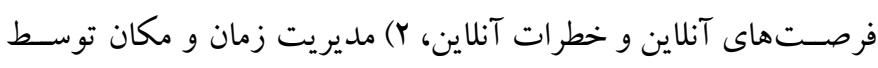

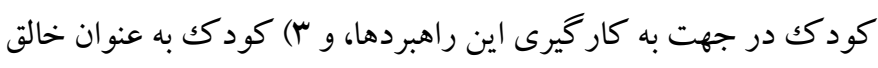

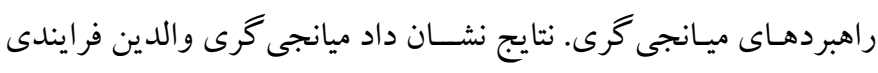

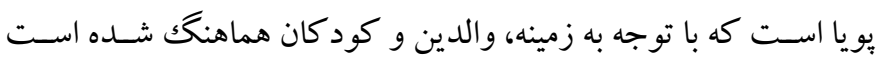

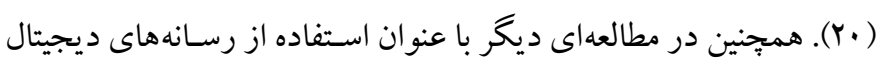
در دانش آموزان دانشًاهى مشخص شد كه استفاده از رسانه هاى ديجيتال

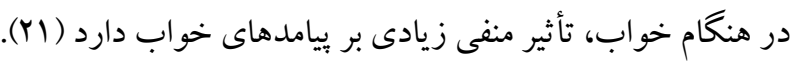

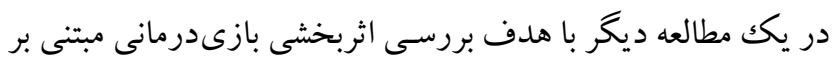

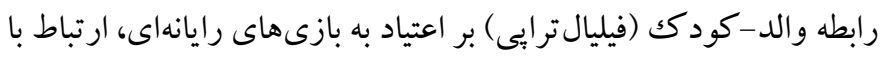

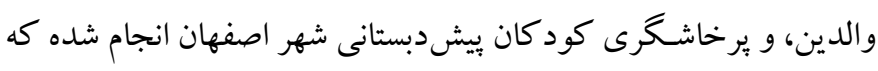

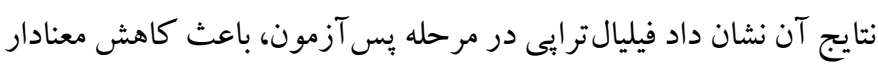

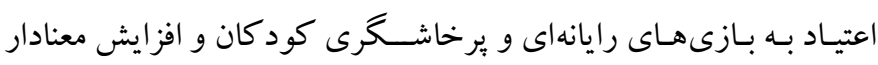

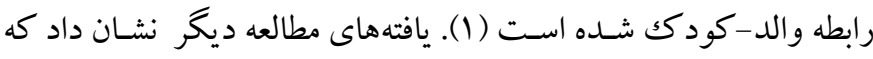

افزايش مى يـابد (1). بيشـتر مطالعاتى كه اختلالات خواب و ارتباط آن با

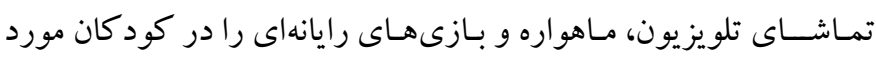

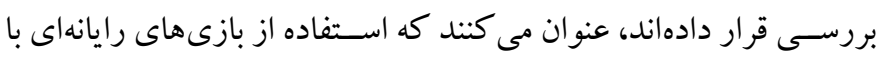

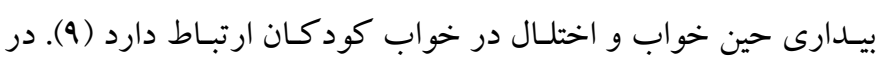
زمينه اهميت و نقش خواب و تأثير اختلالات ناشسى از عادات غير صسحيح

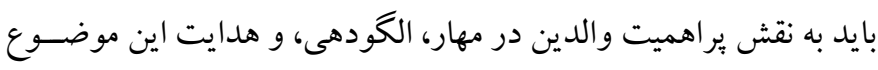

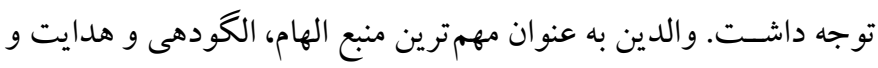

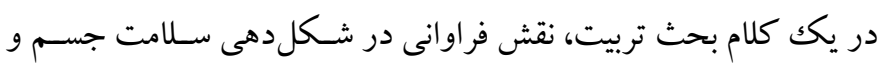

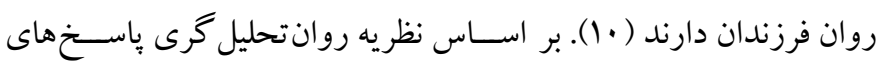

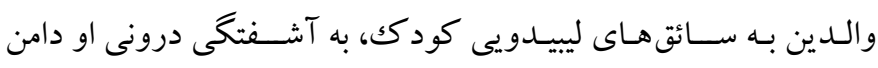

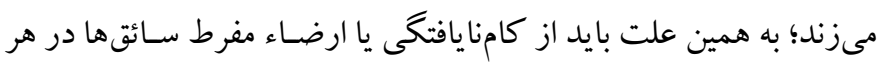

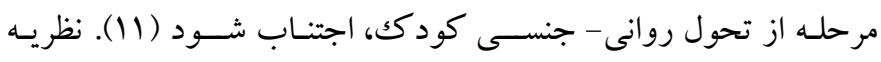

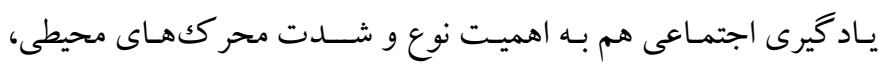

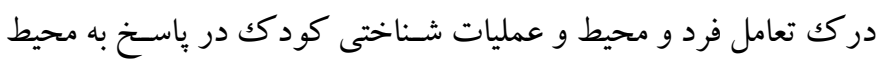

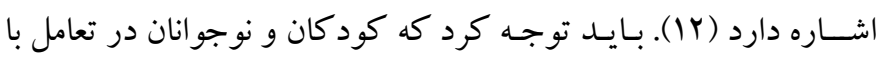

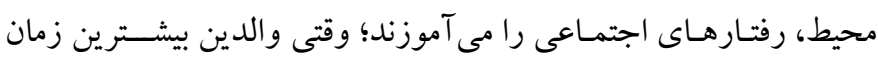

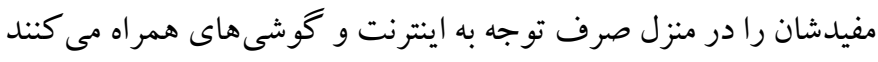

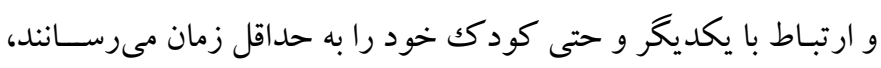

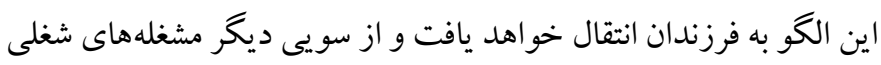

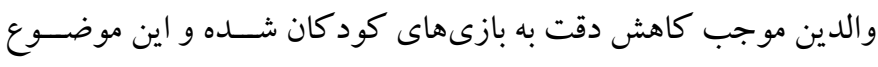

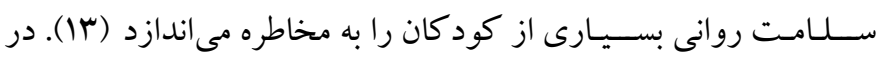
خانو ادههايى كه نظارت و مشـار كت والدين در فعاليتهاى فرزندشـان

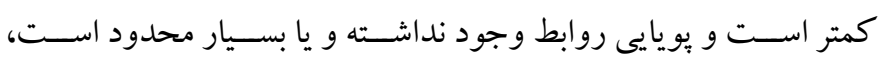
كود كك به جاى تعامل با خانو اده و محيط، به فضاى مجازى بازى رايانهاى

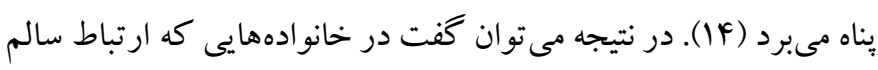
و تعاملات سازش يافته والدين و فرزندان بيشتر است، نه تنها فرزندان كمتر دجار مشـكلات روانى و عاطفى مى شـوند، كه گرُ ايش آنها به اسـتفاده از

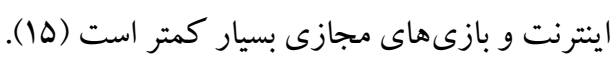
انجام تكاليف مدرسه به صورت آنلاين، داشتن يكك رايانه شخصى و دسترسى به اينترنت در خانه باعث مى شـود كود كان وقت بيشترى را در

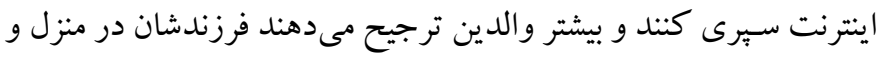


اختلال خواب و همجنين سـاير اختلالات كود كان مى توان الكوى مناسبى

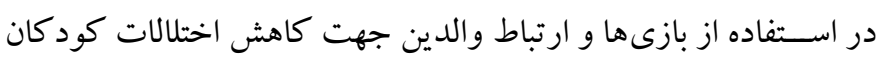

$$
\text { ايجاد كرد. }
$$

روش

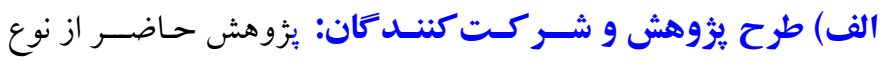

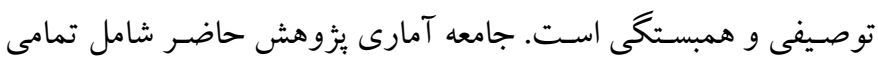

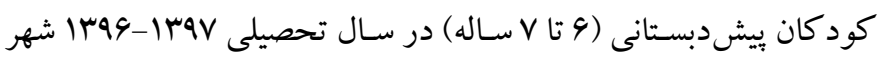

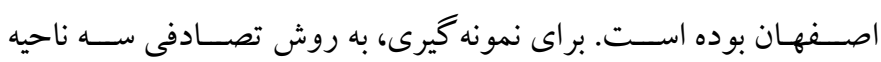

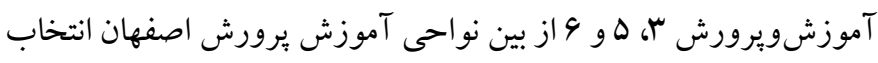

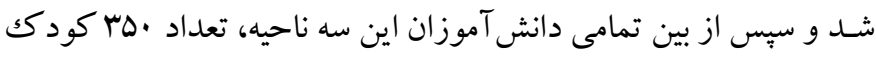
(

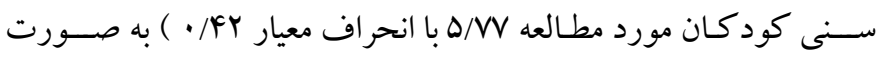

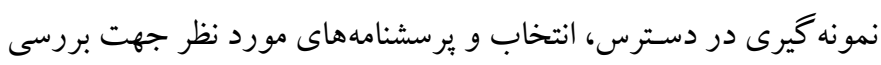

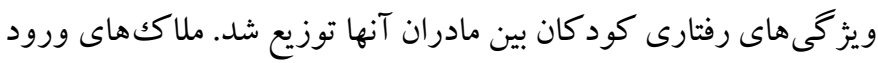

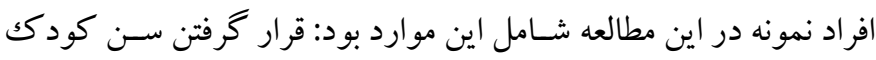
در دوره بيشدبسـتانى بر اسـاس تعريف نظام آموزشـى ايران، اسـتفاده

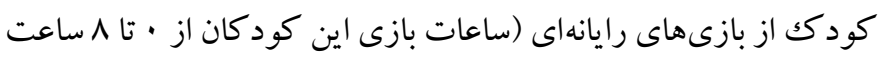

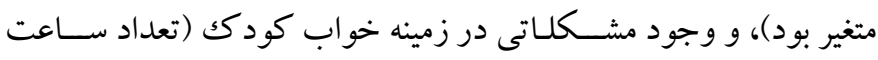

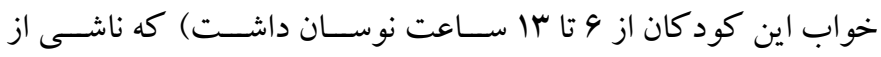

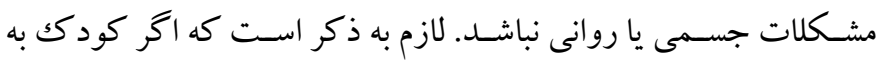

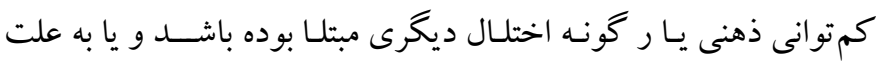

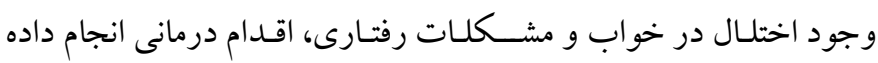
باشد، از نمونه خارج شده است.

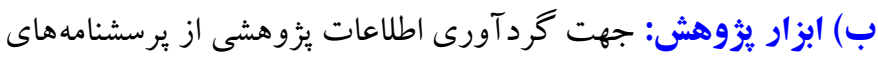
زير استفاده شده است: ا . برسشـنامه اعتياد به بازىهاى رايانهاى": اين برسشنامه توسط سلطانى و

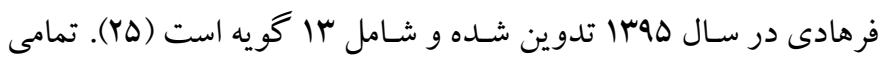

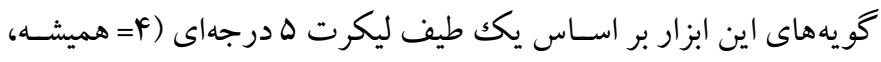

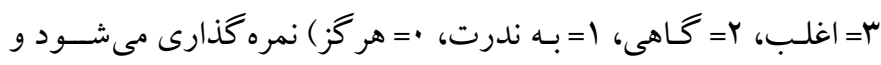
دامنه نمرات در اين يرسشــامه بين · تا ها هـ اسـ. نمره بالاتر، نشاندهنده
بيشـرين اختلالات خواب در كود كان به ترتيب، بيدار شـدن از خواب در

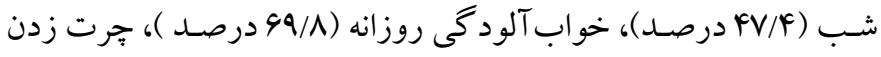
بعد از مدرسـه (94/9 درصـد)، و كابوس شبانه ( (1/1) دابه درصد) بودهه است.

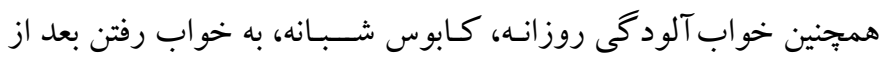
بيـدار شـــدن از خواب، به خواب رفتن در مدرســه، و جرت زدرت زدن بعد از

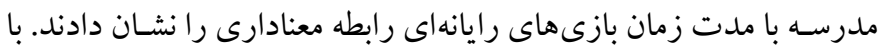

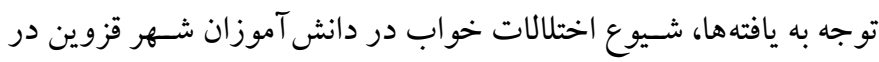

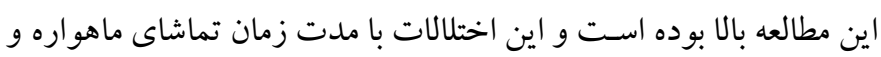

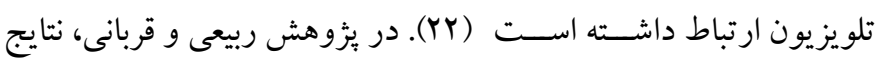
حاكى نشان داد كه بازىهاى رايانهاى: () صميميت والدين و فرزندانشان را كاهش داده اسـت؛ Y) باعث شـده است كه فرزندان، انتظارات والدين

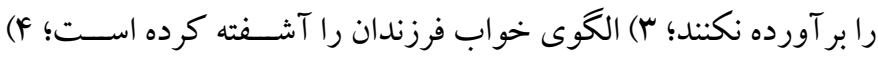

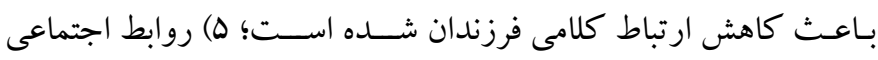

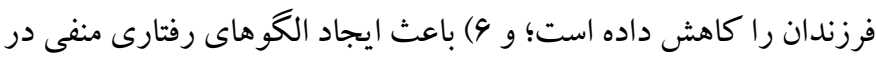

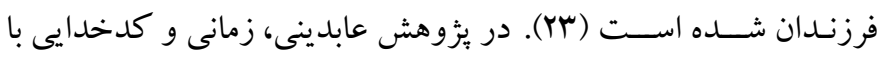

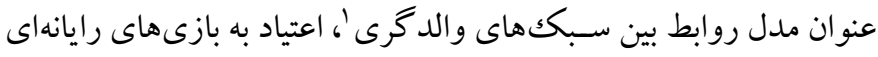

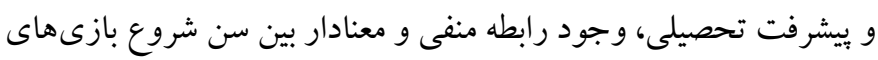
رايـانـهاى و اعتيـاد بـه بـازىهـاى رايـانـهاى؛ و رابطه مثبت و معنادار ميان

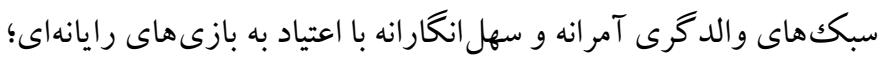

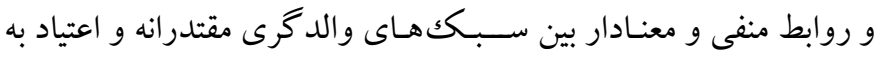

$$
\text { بازىهاى رايانهاى، تأييد شد (YF). }
$$

بايد توجه داشت كه در بيشتر يثوهش هاى انجام شده به بررسى نقش

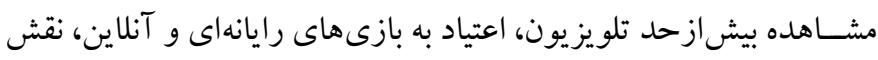

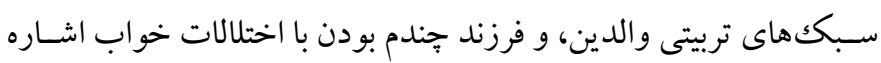

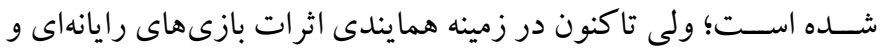

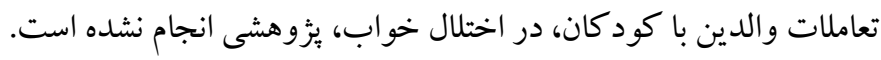

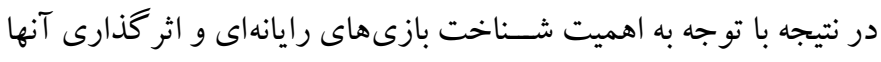

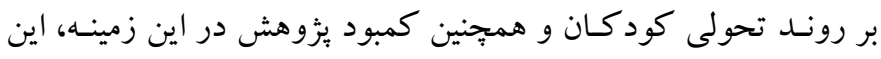

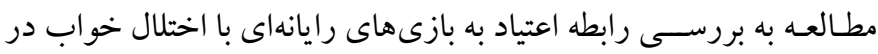

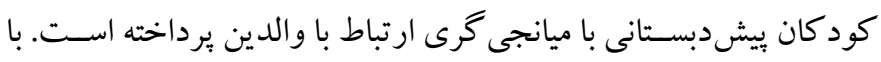

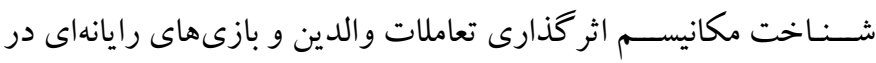

1. Parenting 
ارا علامت گذارى كنند. للازم به ذكر اسـت كه گويه هاى (ا، ب، س، ·1،

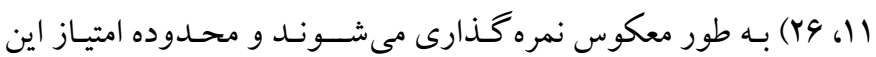
يرسشنامه بين 99-سMاست. نمره هر خردهمقياس از مجموع سؤالات معين به دســت مى آيد. نمرههاى بالاتر در برسـشــنامه عادات خواب به معناى مشـكلات خواب بيشـتر است و بالعكس. اعتبار اين ابزار با روش همسانى درونى (ضـريب آلفاى كرونباخ) براى خردهمقياسها در مقياس اصسلى برابر بـا •V/ • در يـك نمونسه (غير بـالينى) از كود كان بين F تا • ا ســال كزارش شــد و اعتبارسـنجى به روش باز آزمايى با فاصـله دو هفتهاى در محدوده 9Y/ • تا V9/ · به دست آمد. در بزّوهش شوقى، خنجرى، فرمانى و حسـينى، روايى صورى اين ابزار از طريق مصاحبه با والدين و با فرمول

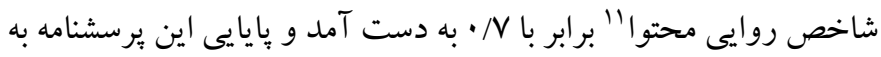
روش باز آزمايى با فاصسله دو هفته در مورد · ا كودكك 9-11 سـاله، 9V/. تعيين شـد. ضـريب آلفاى كرونباخ برسـشـنامه در طى دو مطالعه NV/ • و

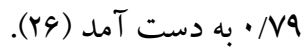

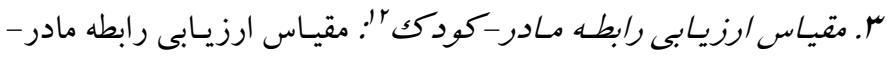
كودك توسط رابرت (1991) از مؤسسه مطالعاتى روانشناختى غرب انتشـار يافته اسـت. اين آزمون يكك مقياس نكرشسـنج اسـت كه ديد كاه مادران را درباره F ســبك تعامل با كود كك، مورد ارزيابى قرار داده و در حيطهـ آزمونهـاى فرافكن قرار مى گيرد. خردهمقيـاسهـاى اين آزمون

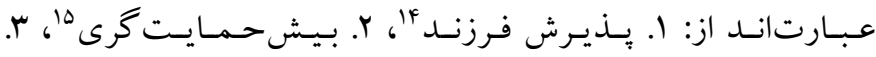

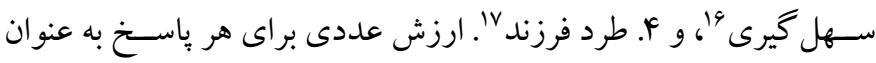
نمره خـام محســوب مى شــود. براى بـهـ دســت آوردن نمره خـام هر خردهمقياس، امتياز عبارات با هم جمع مىشود و هر جه نمره خردهمقياس بالاتر باشـــ، ميزان نخرش بالاتر خواهد بود و هر جهه نمره مقياس پايينتر بـاشــــ، ميزان نكرش كمتر خواهـد بود. نمرات ع خ خردمقيـاس بر روى نيمرخ ترسيم شــده و نقطه •له درصـدى ميانگين محسـوب مى شود. نقطه

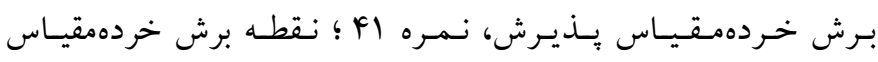

10. Daily drowsiness

11. Content validity ratio (CVR)

12. Mother-Child Relationship Evaluation

13. West Psychological Studies (WPS)

14. Child Acceptance

15. More supportive

16. Negligence

17. Child Rejecting
اعتياد بيشـتر به بازىهاى رايانهاى است و بالعكس. در بثروهش سلطانى و فرهادى، به منظور بر آورد اعتبار برسشنامه، در ابتدا آن را روى ·س نفر يا بيشتر اجرا كردند و از روش دونيمه كردن و آلفاى كرونباخ استفاده شده است. بِس از دونيمه كردن سؤالات برسشنامه اعتياد به بازىهاى رايانهاى و محاسـبه نمرات هر نيمه، مقدار ضـريب همبستخى بين نمرات حاصل از دونيمه كردن، MV/ • و با اسـتفاده از روش اسبيرمن - براون، ضريب بايايى

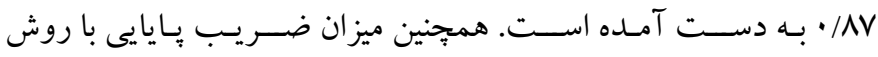
همبستخى درونى آلفاى كرونباخ، •9/ ·به دست آمده كه قابليت اطمينان بالايى را نشـان مى دهد. جهت تعيين روايى صــورى، اين ابزار در اختيار گروهى از مخاطبان (اسـتادان يا دانشسجويان)، قرار داده شـده و رسـايى و واضـــح بودن ظـاهرى گويـهـــا مورد ارزيابى قرار گرفت و جهت تعيين روايى محتو ايى برسـشــنامه، نخسـت آن رابه تأييد ه نفر از اسـتادان و متخصصسان رسانده شده (محدوده ضريب روايى معتبر در هر كويه براى ه نفر، بالاتر از ه/ · به دسـت آمده است) و بدين صورت روايى محتوايى يرسـشـنامه نيز تأييد شـده اسـت (YD). اعتبار اين برسـشــامه در بثزوهش حاضر با روش آلفاى كرونباخ س^/. به دست آمده است. r ب برسشنامه عادات خواب كودكك ': اين برسشنامه توسط اوونز، اسيريتو،

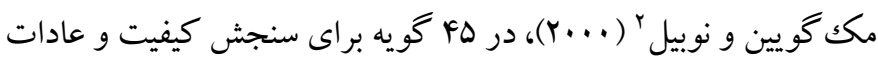
خواب كود كان ساخته شده است كه توسط والدين تكميل مىشود (Y4)

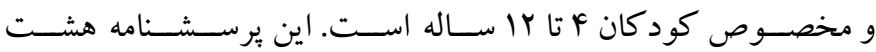
خردممقياس را شـامل مىشـود: () مقاومت در برابر خو ابَّ، Y) تأخير در

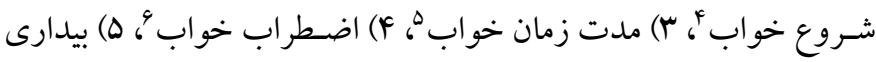

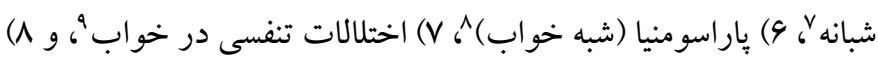
خواب آلود گى روزانه". يرسـشـنامه در قالب طيف ينج درجهاى ليكرت اسـت. در اين ابزار از مادران خواسته مىشـود در صورت تكرار رفتار به

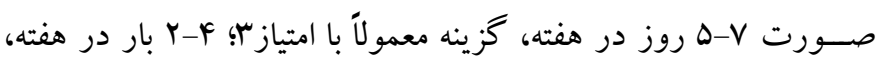
گزينه كاهى اوقات با امتياز ب؛ ا-· بار در هفته، گزينه به ندرت با امتياز

1. Children's Sleep Habits Questionnaire

2. Owens, Spirito, McGuinn \& Nobile

3. Sleep resistance

4. Delayed sleep onset

5. Sleep duration

6. Sleep anxiety

7. Night waking

8. Parasomnia

9. Respiratory disorders in sleep 
جدول 1: شاخصهاى توصيفى

\begin{tabular}{|c|c|c|c|}
\hline ميانغين & انحر اف معيار & مؤلفه ها & مقياس \\
\hline$|F /| \Lambda$ & $9 / \Gamma 1$ & اعتياد به بازىهاى رايانهاى & \multirow{15}{*}{$\begin{array}{l}\overline{3} \\
3 \\
3 \\
3 \\
\overline{3} \\
3\end{array}$} \\
\hline $\mid F V / \Delta r$ & $11 / 4 A$ & ارتباط با والدين & \\
\hline $\mathrm{rq} / .9$ & $\Delta / \cdot 1$ & يذيرش فرزند & \\
\hline$r q / . r$ & $9 / .1$ & بيش حمايت گرى & \\
\hline rq/Aq & $\Delta / 9 r$ & بيشهل گيرى & \\
\hline$r \Delta / \Delta q$ & $\Delta / r$. & طرد فرزند & \\
\hline $1 / 91$ & $\cdot / 4 \Lambda$ & مقاومت در برابر خو اب & \\
\hline $1 / 4$. & .194 & تأخير در شروع خواب & \\
\hline $1 / \Delta r$ & $\cdot / 0$ & مدت زمان خواب & \\
\hline$r / \cdot \Lambda$ & $\cdot / \Delta \Delta$ & اضطراب خواب & \\
\hline $1 / \Delta r$ & $\cdot / 49$ & بيدارى شبانه & \\
\hline $1 / 49$ & $\cdot / r 9$ & 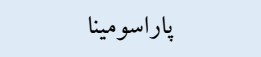 & \\
\hline $1 / 79$ & $\cdot / A r$ & اختلال تنفسى خواب & \\
\hline $1 / \sqrt{ } 9$ & 每 & خوابآلود گى روزانه & \\
\hline $1 / 9$. & $\cdot / T^{4}$ & نمره كل & \\
\hline
\end{tabular}

همان طور كه مشـاهده مى شـود ميانخين اعتياد به بازىهاى رايانهاى

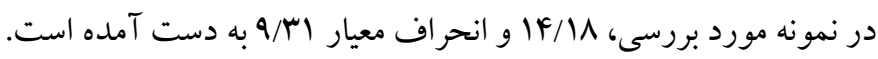

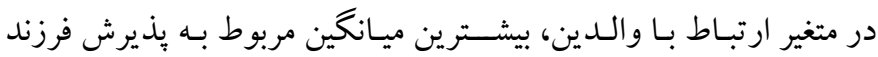

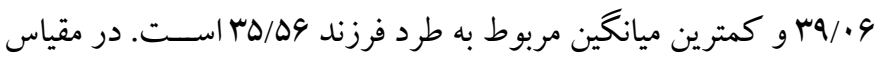

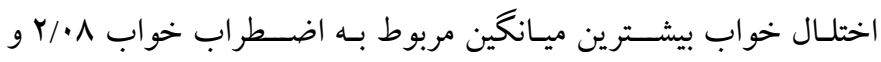

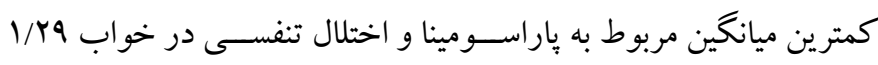

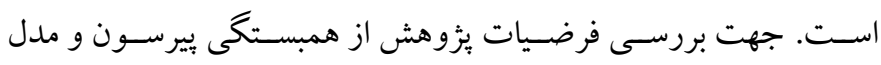

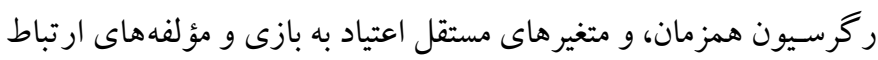

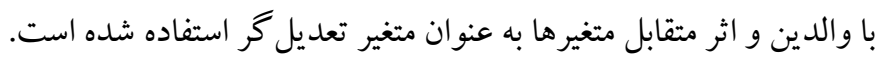

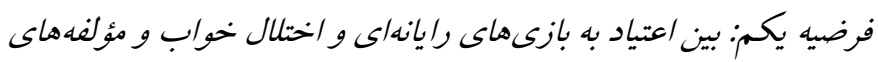

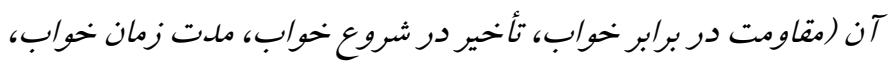

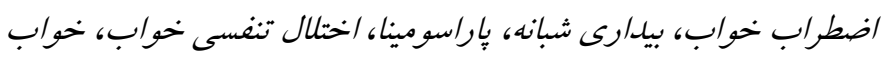
آلودكى روزانه) رابطه وجود دارد.

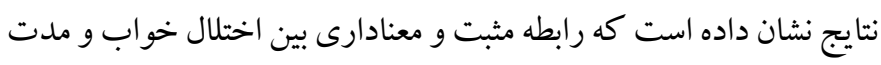

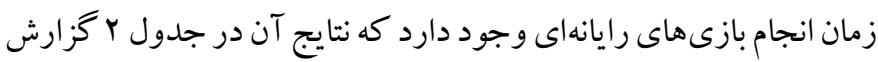

بيش حمايت گرى، نمره MF ؛ نقطه برش خردهمقياس ســهل گيرى، نمره

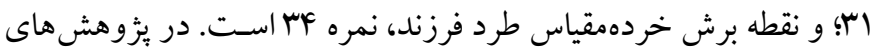

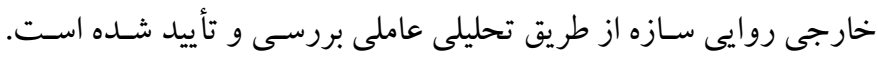

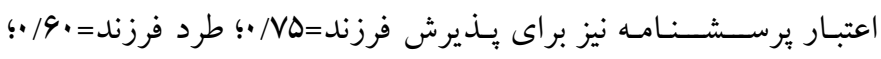

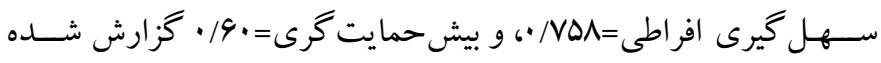

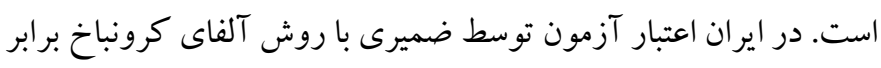

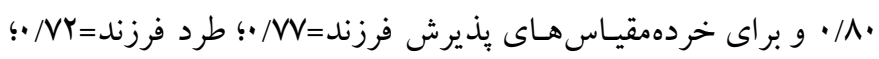

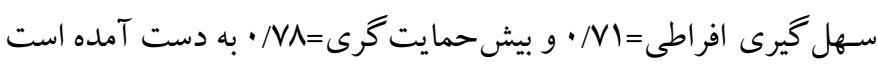

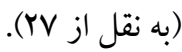

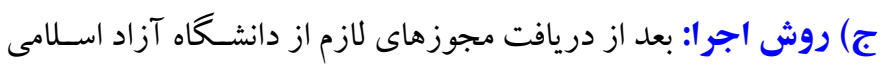

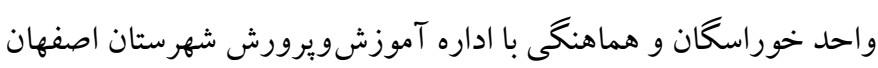

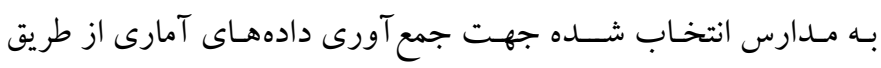

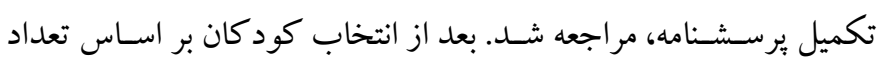

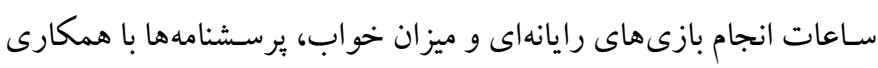

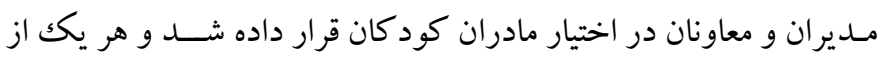

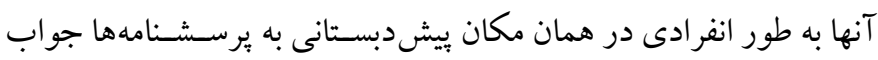

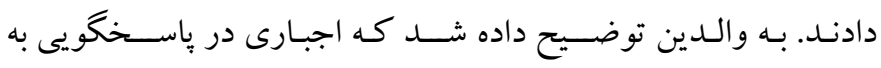

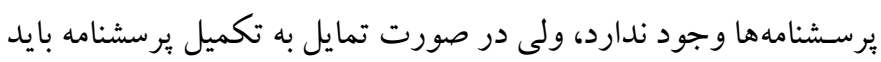
در صـحت اطلاعات دقت للازم را داشـته باشــند. همجينين به آنها اطمينان

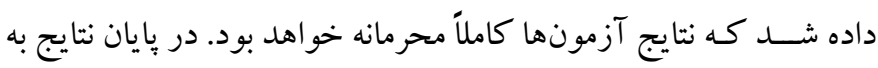

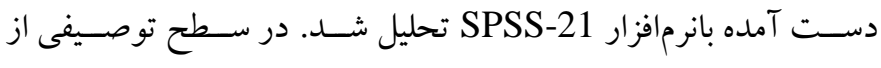

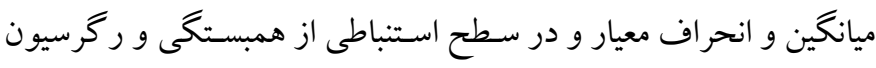
سلسله مر اتبى استفاده شد.

\section{يافتهها} در جدول انمرات به دسـت آمده حاصـل از يافتهاى توصسيفى نمرات

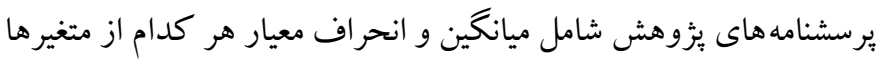
و خردممقياس هاى آنها گزارش شده است. 


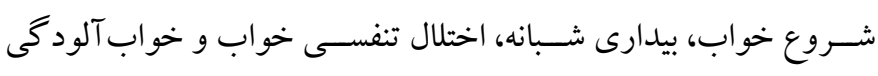

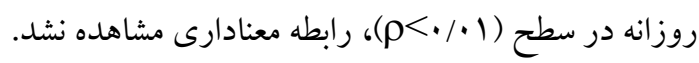

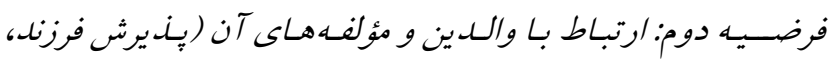

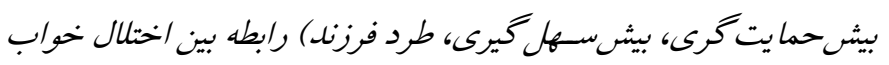
و اعتياد به بازىهاى رايانهاى را تعديل مىكند.

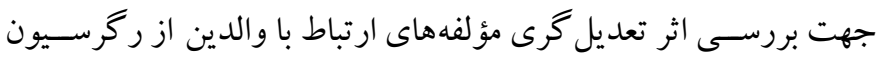

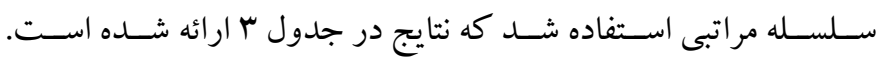

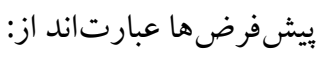

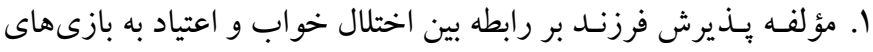

$$
\text { رايانهاى اثر تعديل گرى دارد. }
$$

r. مؤلفه بيش حمايت گرى بر رابطه بين اختلال خواب و اعتياد به بازى تهاى داى

$$
\text { رايانهاى اثر تعديل گرى دارد. }
$$

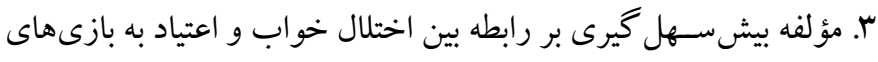

$$
\text { رايانهاى اثر تعديل گرى دارد. }
$$

f. مؤلفهـ طرد فرزنـــ بر رابطه بين اختلـال خواب و اعتيـاد بـه بـازىهاى

\begin{tabular}{|c|c|c|c|}
\hline \multicolumn{2}{|c|}{ اعتياد به بازىهاى رايانهاى } & \multirow{2}{*}{ متغير ها } & \multirow{2}{*}{ رديف } \\
\hline sig & $\mathbf{R}$ & & \\
\hline$\cdot / \cdot$ & $\cdot / Y \Delta$ & مقاومت در برابر خواب & 1 \\
\hline$\cdot / r$ & $.1 \cdot 9$ & تأخير در شروع خواب & r \\
\hline$\cdot / \cdot$ & $\cdot / Y F$ & مدت زمان خواب & r \\
\hline$\cdot / \cdot$ & $\cdot / r F$ & اضطراب خواب & f \\
\hline$\cdot / r 1$ & $.1 \cdot 4$ & بيدارى شبانه & $\Delta$ \\
\hline$\cdot / \cdot$ &.$/ 19$ & باراسومينا & 4 \\
\hline$\cdot / \Delta r$ &.$/$ & اختلال تنفسى خواب & $\checkmark$ \\
\hline$\cdot 199$ & $\cdot / \cdot r$ & خوابآلودگى روزانه & $\wedge$ \\
\hline$\cdot / \cdot$ & $\cdot / Y \wedge$ & نمره كل اختلال خواب & 9 \\
\hline
\end{tabular}

$$
\text { رايانهاى اثر تعديل گرى دارد. }
$$

جدول ז: بررسى رابطه بين اعتياد به بازىهاى رايانهاى و اختلال خواب و

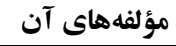

جنانجه در جدول Y مشـاهده مىشود بين اعتياد به بازىهاى رايانهاى

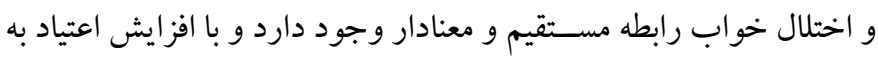

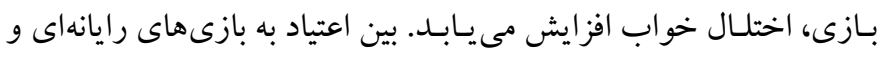

\begin{tabular}{|c|c|c|c|c|c|c|c|c|}
\hline $\mathbf{p}$ & | استاندارد & $\boldsymbol{\beta}$ & $\mathbf{p}$ & $\Delta \mathrm{F}$ & Rr اصلاح شده & متغيرها & مراحل مدل & مؤلفه مورد بررسى \\
\hline & & & $\%$ & $10 / 491$ & $\cdot / \cdot \mathrm{VV}$ & ويز گَى هاى مدل & & \\
\hline$\cdot \cdots$ & . / TAY & $\cdot / \cdot \wedge$ & & & & اعتياد به بازى & 1 & \\
\hline • rar & $-\cdot / \cdot F \Delta$ & $-\cdot / \cdot r \mu$ & & & & مؤلفه يذيرش فرزند & & 3 \\
\hline & & & $\cdot / Q F V$ & $\% r$ & $\cdot \cdot \cdot v^{f}$ & ويز كى هاى مدل & & $\begin{array}{l}43 \\
.3\end{array}$ \\
\hline$\cdot / \cdot$ & $\cdot /$ rAD & $\cdot \cdots \wedge$ & & & & 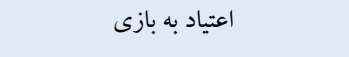 & $r$ & $\hat{3}$ \\
\hline$\cdot / 9 V \Delta$ & $-\cdot / \cdot r$. & $-\cdot / \cdot r$ & & & & مؤلفه بذيرش فرزند & & \\
\hline.$/ Q F V$ & $\cdot / v \mathrm{~V}$ & $\cdot / \cdots$ & & & & اعتياد به بازى * مؤلفه يذيرش فرزند & & \\
\hline $\mathrm{p}$ & 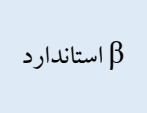 & $\beta$ & $\mathrm{p}$ & $\Delta \mathrm{F}$ & $\begin{array}{c}\text { Rr } \\
\text { اصلاح شده }\end{array}$ & متغيرها & مر احل مدل & مؤلفه مورد بررسى \\
\hline & & & $\cdot / \cdot$ & IV/MAG & $\cdot / \cdot \wedge \Delta$ & ويز تى هاى مدل & & \\
\hline$\cdot \cdots$ & $\cdot / T V F$ & $\% \cdot v$ & & & & 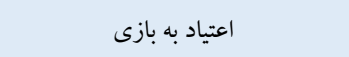 & 1 & \\
\hline$\cdot / \cdot \Delta$ & $-\cdot / 1 \cdot 1$ &.$- / \cdot 01$ & & & & بيش حمايتخرى & & $4 j^{i}$ \\
\hline & & &.$/ \cdot 1 r$ & $9 / 490$ &.$/ .99$ & ويز كى هاى مدل & & 3 \\
\hline$\cdot / \cdot$ & $\cdot / r v$ & $\cdot / \cdot$ & & & & 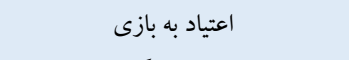 & & $y^{1 / 3}$ \\
\hline • & $-\cdot / \cdot 94$ & $-\cdot / \cdot+\lambda$ & & & & بيش حمايتخرى & r & \\
\hline.$/ \cdot 14$ & $-\cdot /$ YFG & $-\cdot / \cdot v v$ & & & & اعتياد به بازى * بيش حمايتخرى & & \\
\hline $\mathrm{p}$ & 及 & $\beta$ & $\mathrm{p}$ & $\Delta \mathrm{F}$ & $\begin{array}{c}\text { Rr } \\
\text { اصلاح شده }\end{array}$ & متغيرها & مر احل مدل & 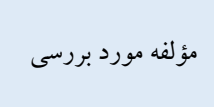 \\
\hline
\end{tabular}
مؤلفـهــاى مـدت زمـان خواب، مقـاومت در برابر خواب، باراســومنيا و اضطر اب خواب رابطه مستقيم و معنادار وجود دارد (1 •/•>م). همجنين در اين يزوهش بين اعتيـاد بـهـ بـازىهـاى رايـانهاى با مؤلفههاى تأخير در

\section{جدول ": تحليل مدل ركرسيونى سلسله مراتبى}




\begin{tabular}{|c|c|c|c|c|c|c|c|c|}
\hline & & & $\cdot / \cdot$ & $M / I F V$ &.$/ .9$ & ويز گیىهاى مدل & & \\
\hline$\cdot / \cdots$ & •/rAY & $\cdot / \cdot v$ & & & & اعتياد به بازى & 1 & \\
\hline$\cdot / \cdot 11$ & $\cdot 1 \cdot 19$ & $\cdot / \cdots \Delta$ & & & & بيشسهل گيرى & \multirow{5}{*}{ r } & $.3 j^{i}$ \\
\hline & & & $\cdot / \Delta \mathrm{r \Delta}$ & $\cdot / 4 \cdot \Delta$ & $\cdot / \cdot M$ & ويز كى هاى مدل & & 卖 \\
\hline$\cdot / M M$ & $\cdot / \Delta$ & $\cdot / \cdots 1$ & & & & اعتياد به بازى & & $y^{2}$ \\
\hline •/4ar & .1 .91 & • & & & & بيشهل گيرى & & \\
\hline •/DTD & - ITMA & $\cdot / \cdots 1$ & & & & اعتياد به بازى * بيشسهل گيرى & & \\
\hline \multirow[t]{2}{*}{$\mathrm{p}$} & \multirow[t]{2}{*}{ م استاندارد } & \multirow[t]{2}{*}{$\beta$} & $\mathrm{p}$ & $\Delta \mathrm{F}$ & $\begin{array}{c}\text { Rr } \\
\text { اصلاح شده }\end{array}$ & متغير ها & \multirow[t]{2}{*}{ مر احل مدل } & مؤلفه مورد بررسى \\
\hline & & & $\cdot / \cdot$ & $I V / V \cdot F$ & $\cdot / \cdot M$ & ويز كى هاى مدل & & \\
\hline$\cdot / \cdots$ & - /TAY & $\cdot / \cdot v$ & & & & اعتياد به بازى & \multirow[t]{3}{*}{1} & \\
\hline$\cdot / \cdot r q$ & $-\cdot / \cdot 19$ & $-\cdot / \cdot \Delta \varphi$ & & & & طرد فرزند & & -2 \\
\hline & & & $\cdot / \mu k$. &.$/ 91 \pi$ & $\cdot / \cdot \wedge \mathrm{V}$ & ويز كى هاى مدل & & के \\
\hline$\cdot / \cdot$ & 每 & $\cdot / \cdot \wedge$ & & & & اعتياد به بازى & \multirow{3}{*}{ r } & \\
\hline$\cdot / 990$ & $-\cdot / \cdot m V$ &.$- / \cdot 19$ & & & & طرد فرزند & & \\
\hline$\cdot / \mu F$ &.$- / .9 V$ & - r./. & & & & اعتياد به بازى * طرد فرزند & & \\
\hline
\end{tabular}

"اعتيـاد بـه بازى - بيش حمايت گرى)، اين فرضـيه هذيرفته مى شــود و به

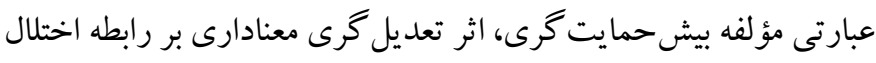

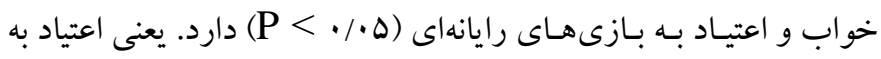

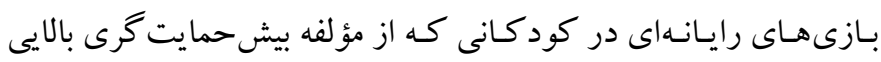

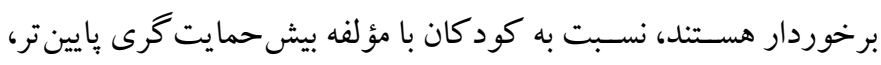

$$
\text { اثر كمترى بر اختلال خواب آنها دارد. }
$$

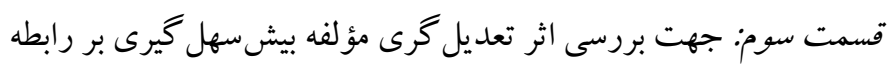

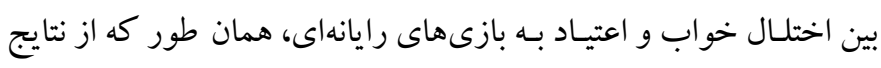

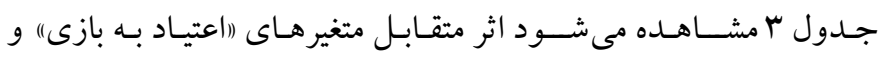

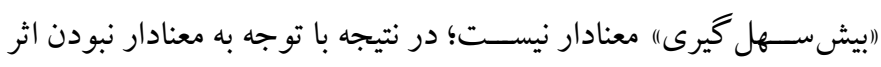

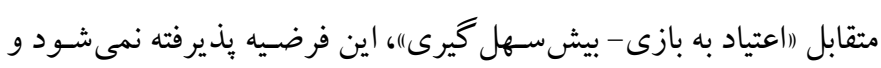

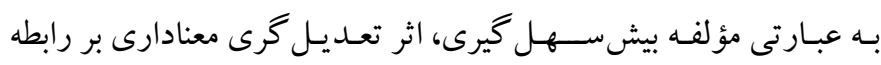
اختلال خواب و اعتياد به بازىهاى رايانهاى (ه • • P (P) ندارد.

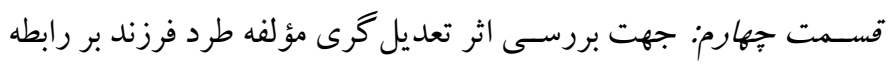

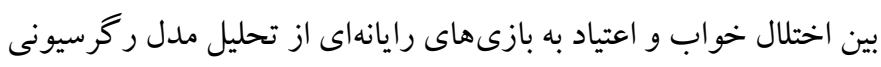
اسـتفاده شـده اسـت. براسـاس نتايج جدول با، مشاهده مى شود اثر متقابل متغيرهاى (اعتياد به بازى)" و (اطرد فرزند) كه وارد مدل شده است، معنادار

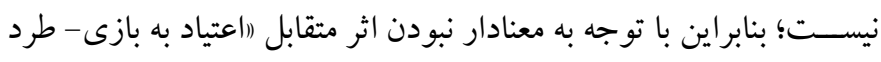

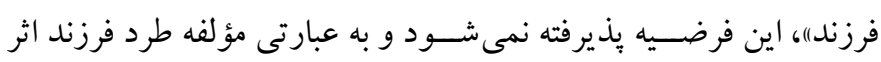

با توجه به نتايج جدول س، مىتوان نتيجه گرفت:

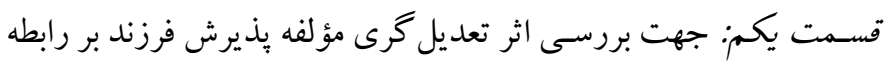

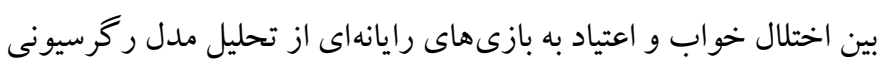

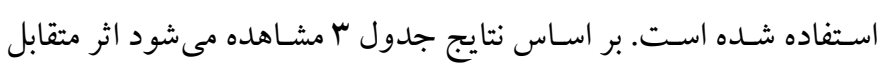

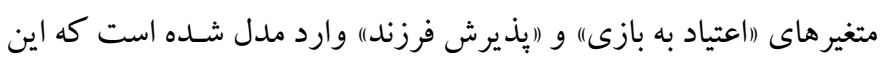

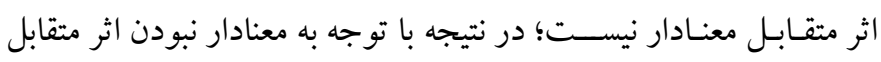

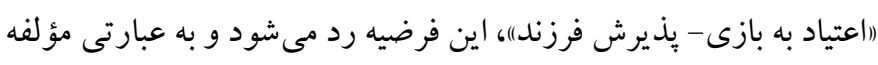
يـذيرش فرزنـد، اثر تعديل گرى معنادارى بر رابطه اختلال خواب و و اعتياد

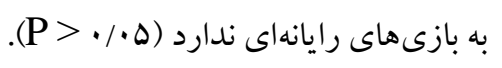

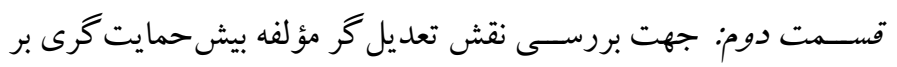

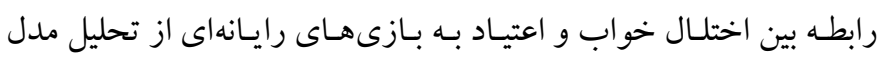

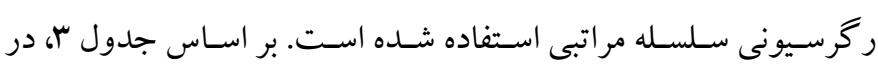

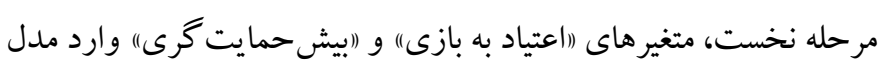

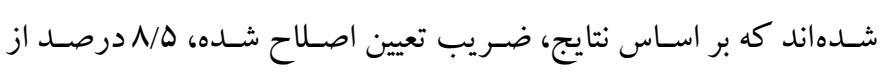

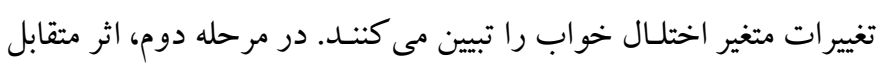

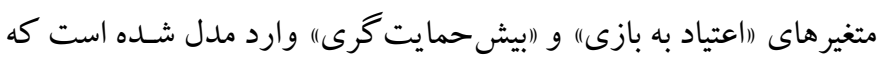
با توجه ميزان DF ارائه شـده براى مدل دوم، اين اثر متقابل معنادار است.

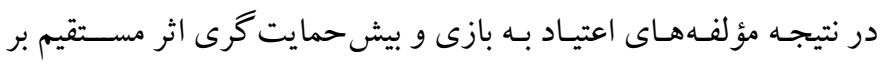

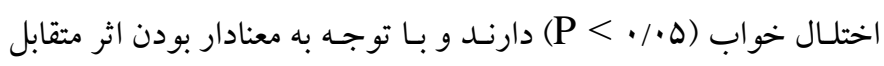


دربـاره خواب، اين گونه تبين كرد كه مجموعه عواملى كه موجب بروز

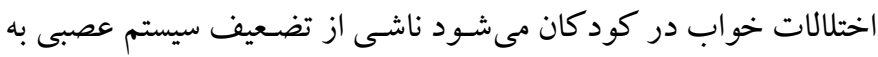

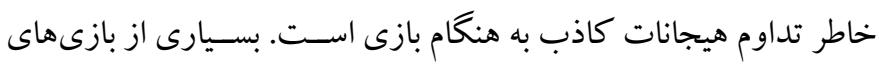

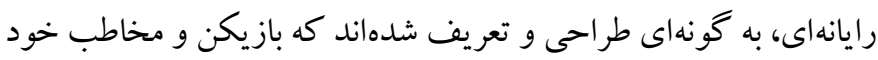

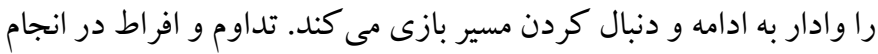

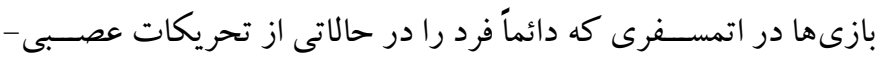

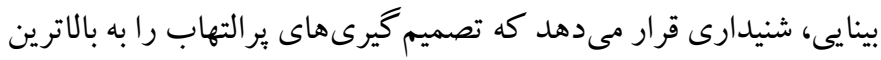

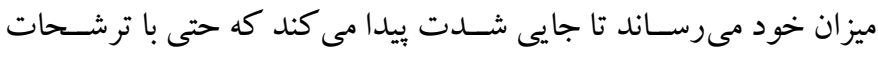
آدرنالين نيز همراه مىشود. زمانى كه سيستمهاى عصبى وجود ناهنجارى را احسـاس مى كند بدن را در بالاترين ميزان هوشـيارى قرار مىدهد و از

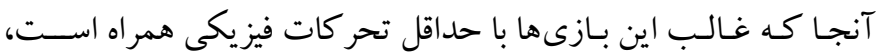

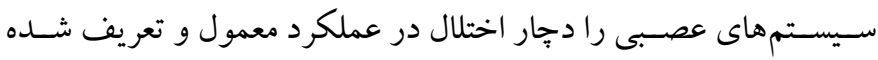

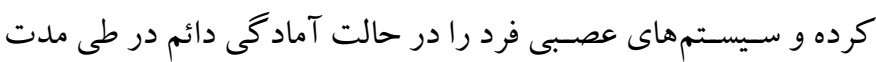
زمان صـرف شــده بازىها مو اجه مى كند. زمانى كه كود كك به صـورت

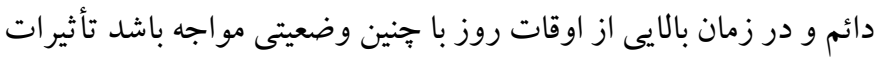

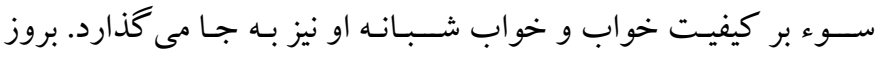
مشــكلـاتى همجيجون بى خوابى، حمله خواب، آينسه خواب، ميو كلونوس

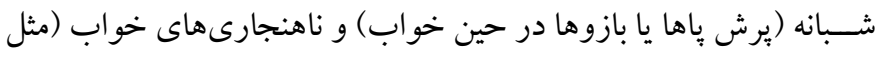

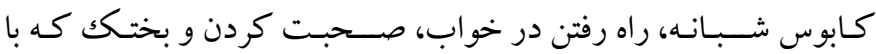
ياراسومنيا معرفى شـده) مجموعهاى از عوارض سوء اثبات شده از افر اط

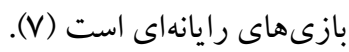
فرضسيه دوم اين يثزوهش به بررسى نوع ارتباط با والدين و مؤلفههاى

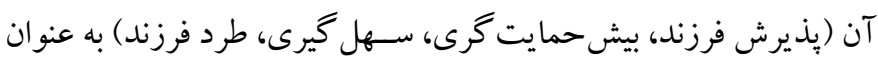

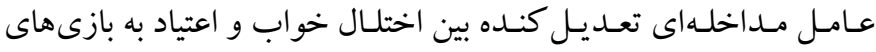

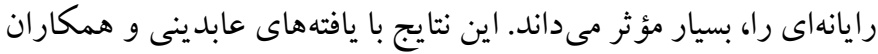

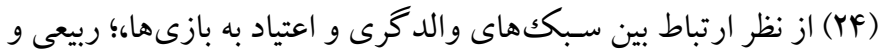
قربـانى (rr) از نظر تأثير متقـابـل بـازىهاى رايانهاى و ارتباط با والدين؛ سماهلو او همكاران (·r) از نظر نقش واسطهاى ارتباط با و الدين و ميزان اســفــاده از فضــاهاى مجازى؛ و جو و لى (I) از نظر ارتباط اعتياد به

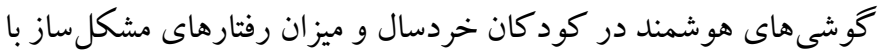
توجه به نقش واسطهاى ارتباط با والدين همسو است. در زمينه اين فرضيه
تعديل گرى معنادارى بر رابطه اختلال خو اب و اعتياد به بازىهاى رايانهاى

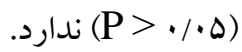

\section{بحث و نتيجه تيرى}

هدف از اين بروهش بررسـى رابطه اعتياد به بازىهاى رايانهاى با اختلال

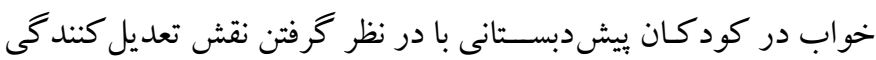

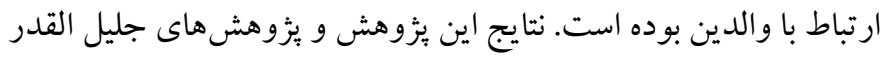

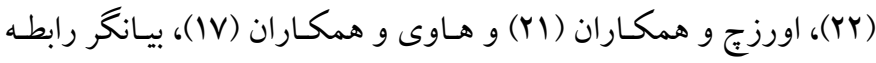
مستقيم بروز اختلالات خواب و عوارض سوء ناشى از آن، با نقش مخرب

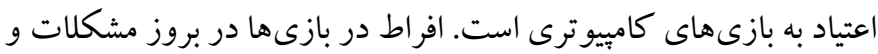
شـات دادن به علائم اختلالات خواب، نقش قابل توجهى دارد و از سويى

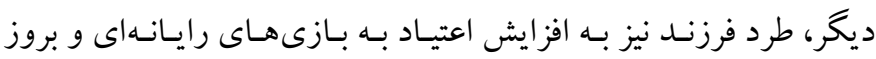

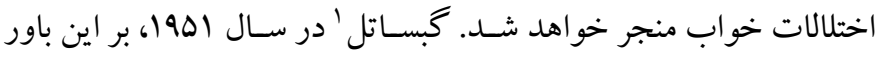

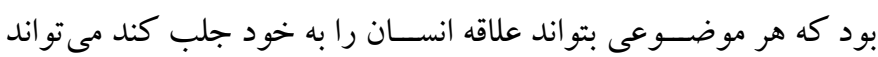

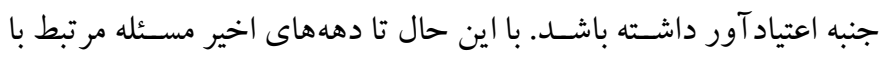
بـازىهـاى رايانهاى تحت عنوان اختلال بازىهاى اينترنتى مورد بررسـى

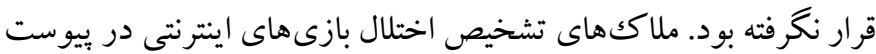

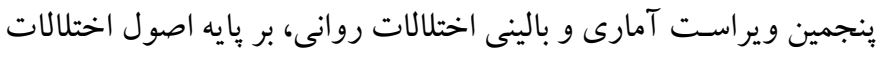

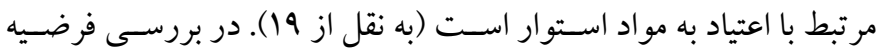
نخسـت اين بزوهش، بين اعتيـاد به بازىهاى رايانهاى با اختلال خواب و

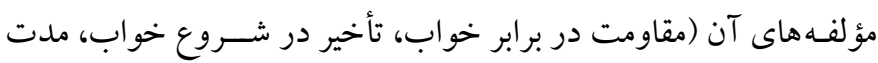
زمان خواب، اضـطر اب خواب، بيدارىهاى شــبانه، بِاراســومنيا، اختلال

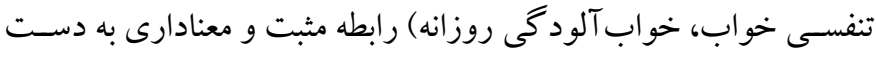

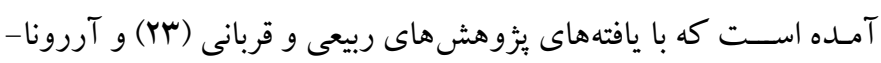

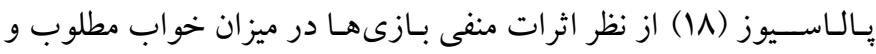
تأثيرات دوجانبه اين بازىها با روابط خانو اد گحى، همسو است.

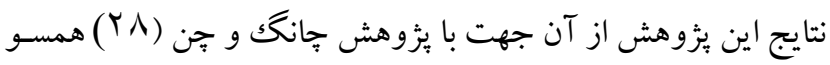

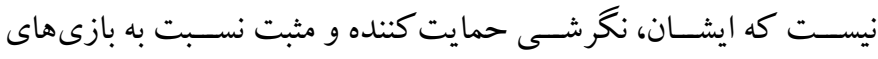

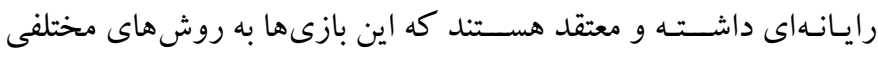

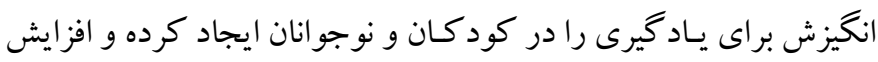
مى دهند. نتيجه به دسـت آمده را مى توان بر اسـاس نظريه فرويد و يونغك ونك

1. Gebsattel 
بازى به عنوان مفرحترين نياز روانى كودك، در كنار كسب تجارب

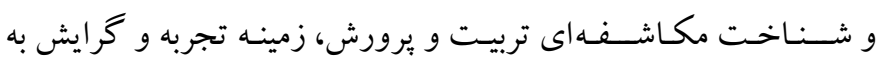

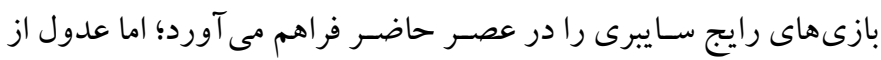

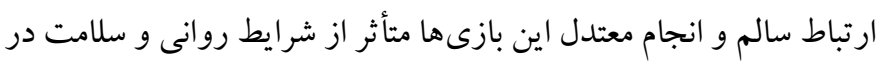

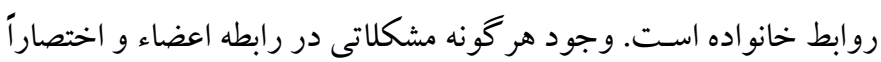
والـد و كودكك تأثيرى غير از شــكاف بين اعضــاء را بـه همر اه ندارد؛

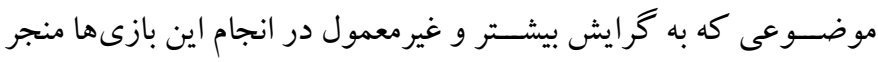

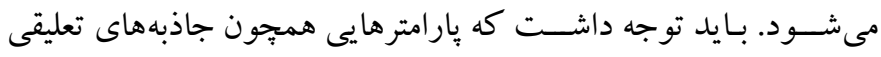

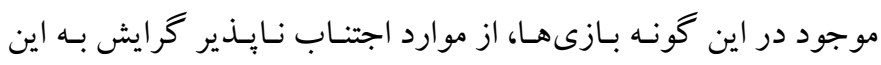

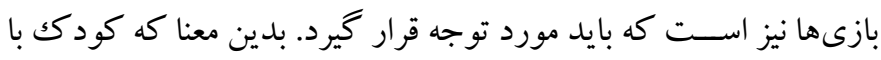

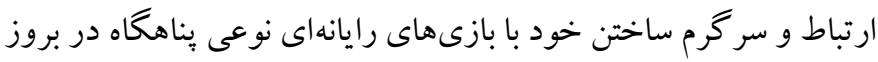

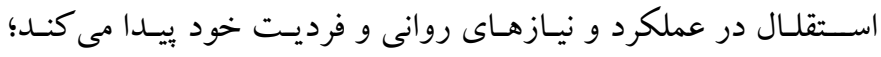

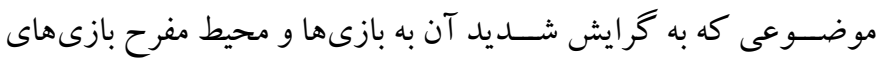

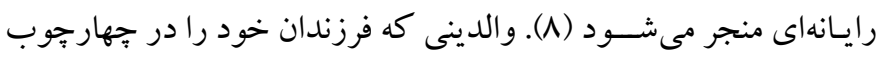

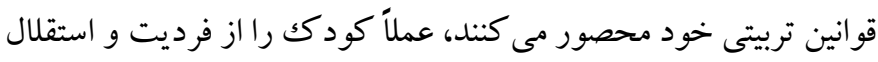

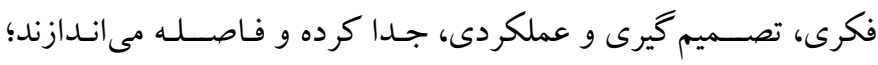

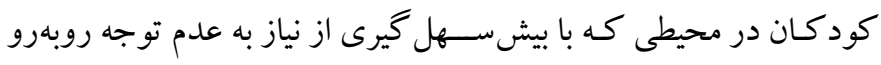

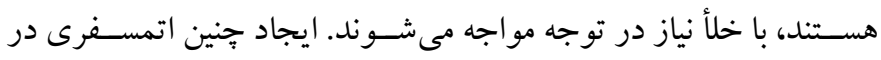

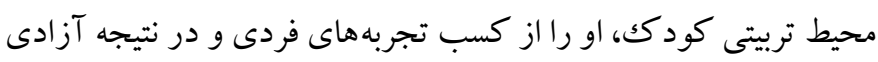
شـناخت در رسـيدن به بينش هاى فردى باز داشــه و حصـارى از قو اعد

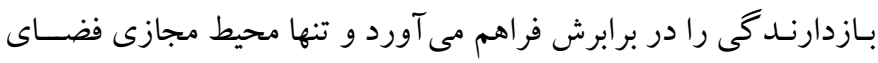

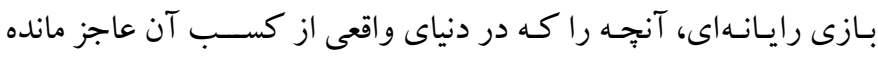

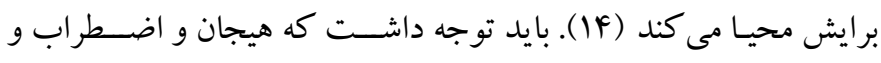
كسب نتيجه ييروزى در مسير انجام بازىها، وقتى با باداش زودرس همراه

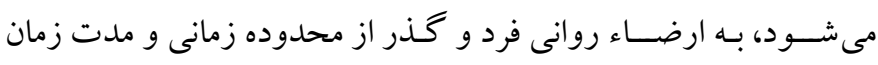
صرف انجام بازى منجر مىشود (Yr). توجه به ارتباط سالم روانى محيط

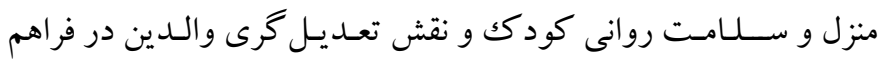

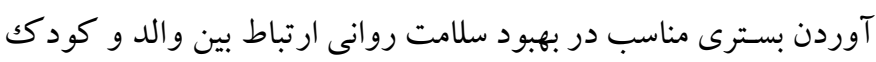

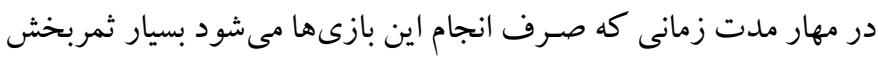

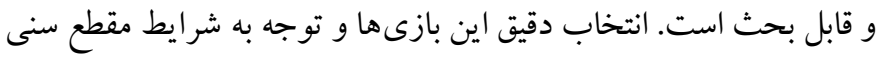

3. Responsiveness
نتيجه ناهمسـو مشـاهده نشــده اسـت. نتيجه به دسـت آمده را مى توان بر اســاس نظريـه روان تحليـل گرى و يـاد گيرى اجتمـاعى و همبِنين نتـايج

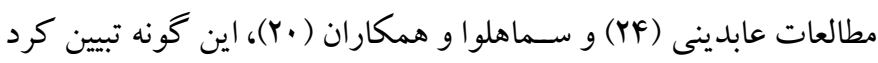

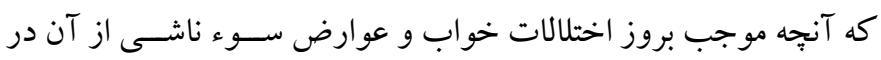

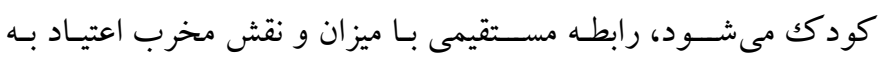

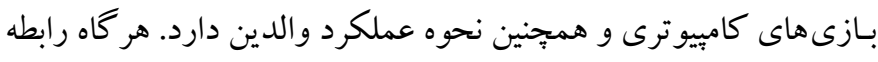

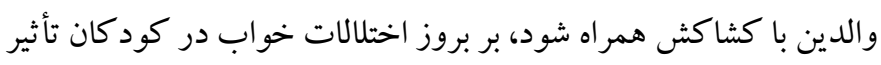

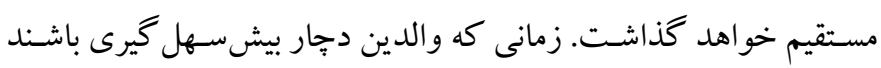

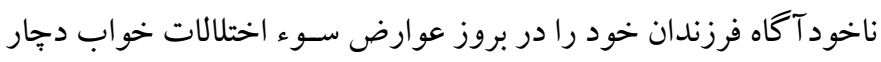
مشـكل مى كنند. كويلن و همكاران، بر اسـاس مفهوم سـازى بامريند'، دو

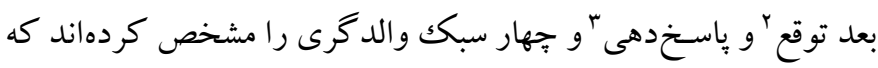

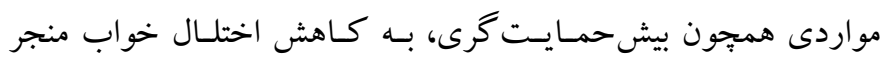

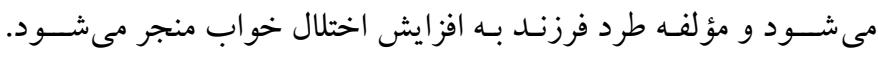

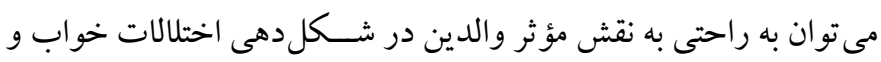

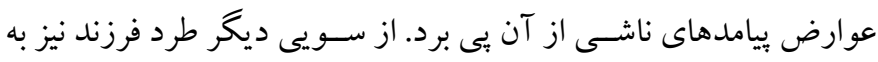

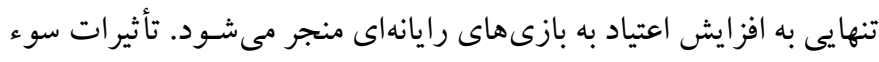

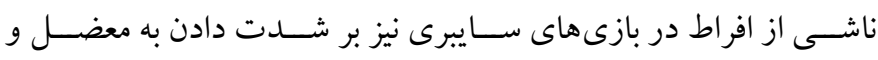

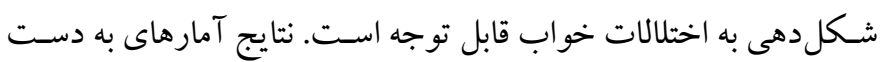

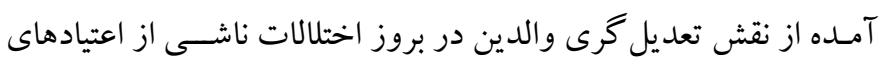

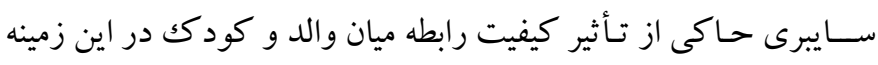

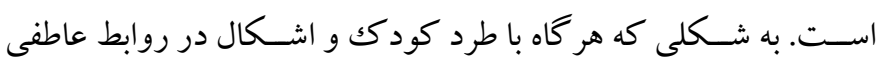

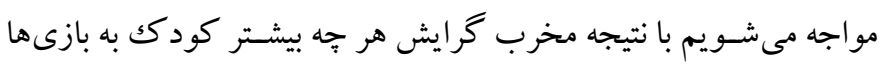

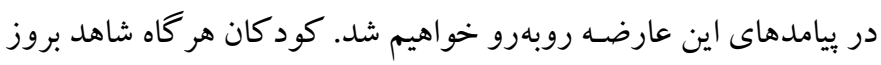

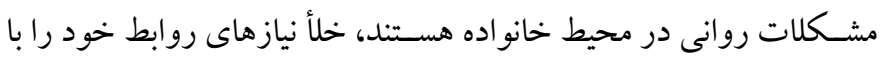

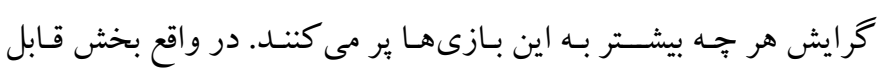
توجهى از ميزان افر اط در اين بازىها متأثر از ســلامت روانى محيط خانه

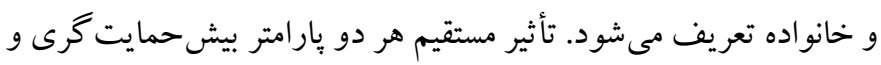

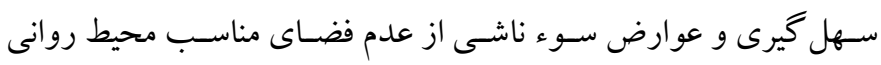

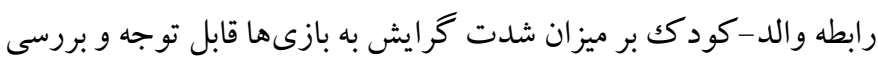

(11) - (1) - (1).
1. Baumrind

2. Demandingness 


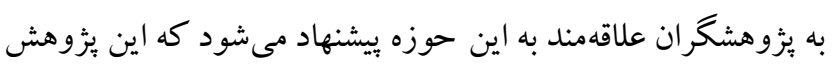
رادر ديكر مقـاطع تحصــيلى، بـا انجـام مصــاحبه بـالينى و اســتفاده از يرسـشـنامههايى جهت بررسـى روابط خانوادگىى، انجام دهند. با توجه به نتيجه فرضيه نخست مبنى بر تأثير بازىهاى يارانهاى بر اختلالات كودكان مىتوان از نتايج به دست آمده در افزايش سلامت روان در مدارس، علوم اعصــاب در حوزه كودكك و نوجوان، مســائل روانى، اجتماعى، تربيتى كود كـان، مـدد كـارى و حمـايـتـهـاى اجتماعى از كود كان و نوجوانان، مر كز توســــه فنـاورى هنرهاى ديجيتال، كانون بازىهاى رايانهاى، نظام ردهبندى سـنى بازىها، انسـتيتو ملى بازىسازى، مركز تحول بازىسازى، بنياد ملى بازىهاى رايانهاى، خانو ادهها، مدارس و مشــاوران كمكك كرد. همجينين روانشـناسـان كودك و خانواده مى تو انند از نتايج اين بثروهش جهت مشـاورههاى تحصسيلى و خانوادگى استفاده كنند و يا با بهره گيرى از بازىهاى رايانهاى در تدريس به انتقال مبانى درسى و آموزشى، كمك كرد. در نتيجه شـناسـايى، تفكيكك و دسـتهبندى كارشـناسـى شــده اين بازىها و بررســى ميز ان عوارض ســوء ناشـى از آنها مى تواند در بروز اختلالات مرتبط، نقش كاهنده داشـته باشـــ. بر اسـاس فرضيه دوم و نقش تعـديل گر خانو اده، به خانوادهها توصــيه مىشــود كه بر نحوه اســتفاده كود كان از رايانه و بازىهاى رايانهاى نظارت دقيق داشـــه باشـــد. البته نظارت بايد به نحوى باشـد كه هويت مسـتل، شـخصـيت و ويز گیىهاى كودكـان هم مورد توجـه قرار كيرد. مـدت زمـان اســفــاده از بازىهاى رايانهاى نيز بايد تحت نظارت و مهار گرى والدين قرار گيرد و به فرزندان خود بيـاموزنــ كـه اسـتفاده از رايانه و بازىهاى رايانهاى نيز مانند ديخر وسايل جمعى بايد در حد متعادل و معين استفاده شود.

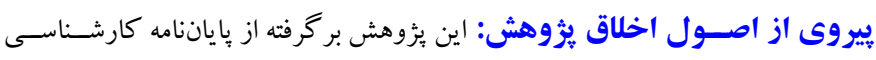

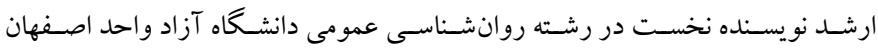

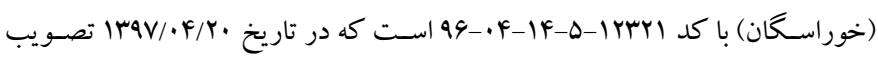
شــده و با كسـب تمامى مجوز هاى علمى و اجر ايى للازم از مؤسـسـهـهاى مربوطه (مجوز

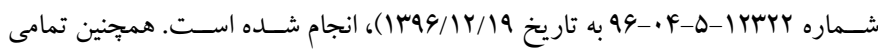
ملاحظات اخلاقى مانند اخذ رضـايتنامه از شـركت كنند كان و حفظ حريم شـخصى و رازدارى در اين مطالعه كاملاً رعايت شده است. حامى مالى: اين مطالعه به طور مستقل و بدون حامى مالى انجام شده است.
و سـلامت و ظرفيت روانى كودكك، فراهم آوردن بسـترهاى مناسـب در انجـام بـازىهـاى ســنتى و متــاول براى كودك در كنـار بهرهورى از بـازىهـايى كه دسـت آوردهاى آموزشـى و تربيتى نيز به همر اه دارند، مى تواند نقش مؤثرى در تعديل بروز اختلالات ناشى از بازىها شود (ها ).

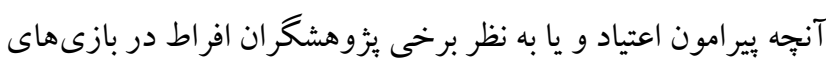
كامييوترى انجام شده، توجه به نقش مخرب و شدت و نوع عوارض سوء ناشـى از آن بوده اسـت. بدون آنكه مجموعه عو امل گر ايش افراط كونه كود كان در نظر كرفته شــود، تنوع و ســـرعت فناورىهاى به كار كرفته شــده در اين بازىها به قدرى زياد اسـت كه غالباً بزوهشـــران حوزه روانسـنجى همواره يكك كام عقبتر از جمعبندى تأثيرات ناشسى از آنها هستـند؛ زيرا كه ابتدا بايد نوعى از سـر گرمى در معرض عموم قرار بـيرد و بعد يُزوهش درباره تأثيرات ناشسى از بازى با اين سـر گرمى انجام شـود. همجينين بايد توجه داشـت كه محصسول ارائه شـده در غالب هر بازى؛ در

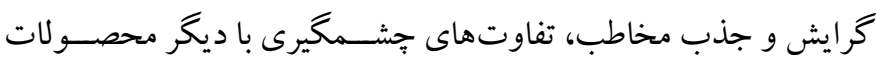
ارائه شـده دارد و بررسـى هر يكك از بازىها در نحوه ساخت و طر احى و فضاى زيباشناسى، نمايشى و اتمسفر كلى به نوبه خود جاى بحث بسيارى در تنوع توليـات و تـأثيرات آن بر روان كودكك و حواشـى همراه آن است. بيشتر ئزوهش هاى انجام شده در اين حوزه به بررسى نقش و ميزان تأثير ات مثبت و منفى محصــولات رايانهاى برداخته اســت، اما به نقش تعديل گر و ميانجى والدين برداخته نشــده اســت كه در اين بززوهش به

$$
\text { بررسى نقش والدين برداخته شده است. }
$$

از محدوديتهاى اين بثروهش مى توان به محافظه كارى و عيب بوشى بسيارى از والدين اشاره كرد؛ بدين معنا كه والدين از ارائه اطلاعات دقيق خوددارى و اجتنـاب ورزيــه و تلـاش مى كردنــ كـه فرزنـدشــان را از خوردن بر جسـب مشكلات روانى محفوظ داشته و به صورت جشمكيرى اختلالاتى كه با آن مواجه هستند را بنهان كنند. همجينين نظرات متفاوت و سـو كيرىهايى طى سالهاى اخير نسبت به اين بازىها مطرح شده است

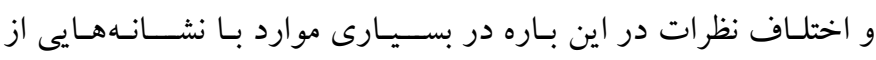
موضـع كيرىهاى غير كارشــناسـانه و بدبينانهاى همر اه مىبود كه دور از دسترس بودن منابع بى طرف، از محدوديت ديخر اين بثروهش بود. جامعه آمارى يززوهش حاضر محدود به مادران كود كان ييشدبستانى بوده است و اين موضوع نيز از ديخر محدوديت هاى اين بزوهش به حساب مى آيد. 
تشـكر و قدردانى: بدين وسـله از مســؤل ان دانشـكاه آزاد اسـلامى واحد اصـفهان

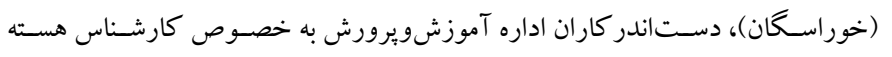

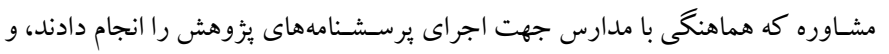

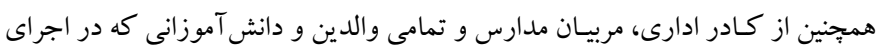
اين طرح به ما كمكك كردند، تشكر و قدردانى مى مشود.
نقش هر يكك از نويسـند كان: نويسـنده نخست اين مقاله به عنوان مجرى اصلى اين

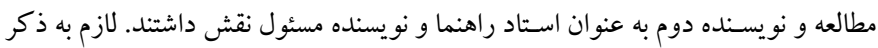
است كه همه نويسند كان دست نوشته نهايى را خوانده و تأييد كردهاند. تضاد منافع: اين ئزوهش براى نويسند كان هيج گونه تضاد منافعى نداشته است. 


\section{References}

1. Soltani M. Farhadi H. The effect of play therapy based on parent-childs' relationship (Filial Therapy) on game addiction and aggression in preschoolers' children. Knowledge \& Research in Applied Psychology. In press; DOI: 10.30486/JSRP.2019.1864194.1742. [Persian]. [Link]

2. Eickhoff LT.E, Yung K, Davis D.L, Bishop F, Klam CWP, Doan AP. Excessive Video Game Use, Sleep Deprivation, and Poor Work Performance Among U.S. Marines Treated in a Military Mental Health Clinic: A Case Series. Military Medicine. 2015; 180, 7:e839-843. [Link]

3. Cortese S, Ramtekkar U, Angriman M. Sleep disorders in children and adolescents: a practical guide. June 2014, In book: IACAPAP Textbook of Child and Adolescent Mental Health. Publisher: International Association for Child and Adolescent. Psychiatry and Allied ProfessionsEditors: Rey JM editor. [Link]

4. Owens JA, Rosen CL, Mindell JA. Medicationn use in the Treatment of Pediatric insomnia: result of survey of community based pediatricians. Pediatrics. 2003; 111(5 pt 1) [Link]

5. Mohsenzadeh A, Farhadi. A, Tarahi. MJ, Pedram.A. Prevalence of Sleep Disorders in School Children Aged Under Study in the City of Khorramabad 7_12 86_85 Academic Year. Lorestan University of Medical Sciences J; 2006: 11(3). URL: http://yafte.lums.ac.ir/article-1-162-fa.html. [Persian]. [Link]

6. Feyzabadi Z, Jafari F, Feizabadi PS, Ashayeri H, Esfahani MM, BadieeAval S. Insomnia in Iranian Traditional Medicine. Iran Red Crescent Med J. 2014; 16(3):e15981. [Persian]. [Link]

7. Griffiths, M. Online video gaming: what should educational psychologists know? Educational Psychology in Practice. 2010; 26(1): 35- 40. [Link]

8. Keaten J, Cheng M. Compulsive video-game playing could be mental health problem. Associated Press. 2018, June 18. https://www.mysanantonio.com/business/technology/ article/Compulsive-video-game-playing-could-bemental-13005158.php [Link]

9. Hale L, Guan S. Screen Time and sleep among schoolaged children and adolescents: A systematic literature review. Sleep Med Rev. 2015. 21: 50-8. [Link]

10. El-Sheikh M, Kelly RJ, Buckhalt JA, et al.Children's sleep and adjustment over time: The role of socioeconomic context. Child development. 2010; 81(3): 83-870. [Link]
11. Coplan, R. J., Hastings, P. D., Lagace-Seguin, D. G., \& Moulton, C. E. Authoritative and authoritarian mothers' parenting goals, attributions, andemotions across different childrearing contexts. Parenting: Science and Practice. 2002 (2): 1-26. [Link]

12. Cho K S, Lee J M. Influence of smartphone addiction proneness of young children on problematic behaviors and emotional intelligence: Mediating self-assessment effects of parents using smartphones. Computers in Human Behavior. 2017; 66, 303-311. [Link]

13. Zhen R, Liu R.D, Hong W, Zhou X. How do Interpersonal Relationships Relieve Adolescents' Problematic Mobile Phone Use? The Roles of Loneliness and Motivation to Use Mobile Phones. Int J Environ Res Public Health. 2019; 16(13): 2286. [Link]

14. Schneider L.A, King D.L, Delfabbro P.H. Family factors in adolescent problematic Internet gaming: A systematic review. J Behav Addict. 2017; 6(3):321333. [Link]

15. Tajalli F, Zarnaghash M. Effect of Family Communication Patterns on Internet Addiction. Journal of Practice in Clinical Psychology. 2017; 5(3), 159-166. [Link]

16. Sipal R.F, Bayhan P. Preferred computer activities during school age: Indicators of internet addiction. Procedia Social and Behavioral Sciences, 2010; 9: 1085-1089. [Link]

17. Hawi, N. S., Samaha, M., \& Griffiths, M. D. Internet gaming disorder in Lebanon: Relationships with age, sleep habits, and academic achievement. Journal of behavioral addictions. 2018; 7(1): 70-78. [Link]

18. Arrona-Palacios, A. High and low use of electronic media during nighttime before going to sleep: A comparative study between adolescents attending a morning or afternoon school shift. Journal of adolescence. 2017; 61, 152-163. [Link]

19. King D L, Herd M C, Delfabbro P H. Motivational components of tolerance in Internet gaming disorder. Computers in Human Behavior. 2018; 78, 133-141. [Link]

20. Smahelova M, Juhová D, Cermak I, Smahel D. Mediation of young children's digital technology use: The parents' perspective. Cyberpsychology: Journal of Psychosocial Research on Cyberspace. 11(3). [Link]

21. Orzech K M, Grandner M A, Roane B M, Carskadon $\mathrm{M}$ A. Digital media use in the $2 \mathrm{~h}$ before bedtime is associated with sleep variables in university students. Computers in human behavior. 2017; 55, 43-50. [Link] 
22. Jalil Al-ghadr SH, Hashemi F, Yazdi Z. Relation of Sleep Disorders by Watching TV, Satellite and Using Computer Games in Elementary Students of Qazvin. JQUMS. 2017; 21(2): 31-40. [Persian]. [Link]

23. Rabiei M, Ghorbani M. (2015). The Effect of Computer Games on Family Relations and Children of the First National Computer Games Conference. [Persian]. [Link]

24. Zamani A, Abedini y. Structural model of the effect of parenting styles and computer game addiction on academic performance in male students, Journal of New Educational Approaches. 2013; 8 (2):133-156. [Persian]. [Link]

25. Soltani M, Farhadi, H. The effect of play therapy based on parent-Childs' relationship (Filial Therapy) on game addiction and aggression in preschoolers' children. Knowledge \& Research in Applied Psychology. Available Online from 15 September 2019. Doi:10.30486/JSRP.2019.186419 4.1742 [Link]

26. Shoghi, M. Khanjari, S. Farmani, F. \& Hoseini, F. Evaluation of sleep patterns of school-aged children residing. Iranian Journal of Nursing. 2005; 18 (43): 83-89. [Persian]. [Link]

27. Roth, R.M. Mother-Child Relationship Evaluation (MCRE). Mother-child relationship: Razmyar, H. Azmonyar pooyainstitution. 2009. [Link]

28. Chuang, T.Y. Chen, W.F. (2009). Effect of ComputerBased Video Games on Children: An Experimental Study. Educational Technology \& Society. 12(2):110. [Link] 